\title{
Neuromodulation Can BeSimple: Myoinhibitory Peptide, Contained in Dedicated Regulatory Pathways, Is the Only Neurally-Mediated Peptide Modulator of Stick Insect Leg Muscle
}

\author{
${ }^{\circledR}$ Sander Liessem, ${ }^{1 *}$ Daniel Kowatschew, ${ }^{2}$ Stefan Dippel, ${ }^{3}{ }^{\circledR}$ Alexander Blanke, ${ }^{1}{ }^{\circledR}$ Sigrun Korsching, ${ }^{2}$ \\ ${ }^{\circledR}$ Christoph Guschlbauer, ${ }^{1}$ Scott L. Hooper, ${ }^{4}{ }^{\circledR}$ Reinhard Predel, ${ }^{1}$ and ${ }^{\circledR}$ Ansgar Büschges ${ }^{1 *}$ \\ ${ }^{1}$ Department of Biology, Institute of Zoology, University of Cologne, Cologne D-50674, Germany, ${ }^{2}$ Institute for Genetics, University of Cologne, \\ Cologne D-50674, Germany, ${ }^{3}$ Department of Developmental Biology, Georg-August-University Göttingen, Göttingen D-37077, Germany, and \\ ${ }^{4}$ Department of Biological Sciences, Ohio University, Athens, Ohio 45701
}

In the best studied cases (Aplysia feeding, crustacean stomatogastric system), peptidergic modulation is mediated by large numbers of peptides. Furthermore, in Aplysia, excitatory motor neurons release the peptides, obligatorily coupling target activation and modulator release. Vertebrate nervous systems typically contain about a hundred peptide modulators. These data have created a belief that modulation is, in general, complex. The stick insect leg is a well-studied locomotory model system, and the complete stick insect neuropeptide inventory was recently described. We used multiple techniques to comprehensively examine stick insect leg peptidergic modulation. Single-cell mass spectrometry (MS) and immunohistochemistry showed that myoinhibitory peptide (MIP) is the only neuronal (as opposed to hemolymph-borne) peptide modulator of all leg muscles. Leg muscle excitatory motor neurons contained no neuropeptides. Only the common inhibitor (CI) and dorsal unpaired median (DUM) neuron groups, each neuron of which innervates a group of functionally-related leg muscles, contained MIP. We described MIP transport to, and receptor presence in, one leg muscle, the extensor tibiae (ExtTi). MIP application reduced ExtTi slow fiber force and shortening by about half, increasing the muscle's ability to contract and relax rapidly. These data show neuromodulation does not need to be complex. Excitation and modulation do not need to be obligatorily coupled (Aplysia feeding). Modulation does not need to involve large numbers of peptides, with the attendant possibility of combinatorial explosion (stomatogastric system). Modulation can be simple, mediated by dedicated regulatory neurons, each innervating a single group of functionally-related targets, and all using the same neuropeptide.

Key words: micro computed tomography; muscle physiology; myoinhibitory peptide; neuropeptide function; single-cell mass spectrometry; transcriptomics

\section{Significance Statement}

Vertebrate and invertebrate nervous systems contain large numbers (around a hundred in human brain) of peptide neurotransmitters. In prior work, neuropeptide modulation has been complex, either obligatorily coupling postsynaptic excitation and modulation, or large numbers of peptides modulating individual neural networks. The complete stick insect neuropeptide inventory was recently described. We comprehensively describe here peptidergic modulation in the stick insect leg. Surprisingly, out of the large number of potential peptide transmitters, only myoinhibitory peptide (MIP) was present in neurons innervating leg muscles. Furthermore, the peptide was present only in dedicated regulatory neurons, not in leg excitatory motor neurons. Peptidergic modulation can thus be simple, neither obligatorily coupling target activation and modulation nor involving so many peptides that combinatorial explosion can occur.

Received Jan. 23, 2020; revised Jan. 5, 2021; accepted Jan. 12, 2021.

Author contributions: S.L., S.K., C.G., S.L.H., R.P., and A.Bü. designed research; S.L., D.K., and S.D. performed research; D.K., S.D., and A.Bl. contributed unpublished reagents/analytic tools; S.L., D.K., and S.K. analyzed data; S.L., C.G., and S.L.H. wrote the paper.

Acknowledgments: We thank Lapo Ragionieri (Institute of Zoology, University of Cologne) for help with sample preparation for transcriptome sequencing, Marek Franitza and Janine Altmüller for transcriptome sequencing (Cologne Center for Genomics), and Michael Dübbert and Jan Sydow for technical assistance (Institute of Zoology, University of Cologne). We thank Fabian Wilde and Jörg Hammel at the German Electron Synchrotron Accelerator Facility (DESY) for the excellent support. S.L. is a member of the Graduate School for Biological Sciences (GSFBS) Cologne and the DFG-RTG1960 “Neural
Circuit Analysis on the Cellular and Subcellular Level." This work was supported by Deutsche Forschungsgemeinschaft Grants PR766/11-1 and 233886668/GRK1960 and by the European Research Council under the European Union's Horizon 2020 Research and Innovation Program Grant 754290, "Mech-Evo-Insect" (to A.BI.). SR $\mu$ CT was carried out under proposal I-20170190.

The authors declare no competing financial interests.

Correspondence should be addressed to Sander Liessem at sanderliessem@web.de or Ansgar Büschges at ansgar.bueschges@uni-koeln.de.

https://doi.org/10.1523/JNEUROSCI.0188-20.2021

Copyright $\odot 2021$ the authors 


\section{Introduction}

Behavior varies as external demand and internal state change. One mechanism underlying this variability is neuromodulation. Neuromodulation has been best studied in invertebrates. In Aplysia, two cholinergic motor neurons that innervate one muscle co-release three peptides (Cropper et al., 1987; Weiss et al., 1992). Peptidergic co-transmission by excitatory motor neurons is also present in other systems (Bishop et al., 1987; Norris and Calabrese, 1987; Bartos et al., 1994; Davis et al., 2001; Dunn and Mercier, 2005; Ormerod et al., 2016). In Tritonia, serotonin released from one network neuron acts on other network neurons through both ionotropic and metabotropic receptors (Katz and Frost, 1996). Single neurons co-releasing activating (ionotropic receptor mediated) and modulatory (metabotropic receptor mediated) transmitters obligatorily couples target activation and modulation. For instance, in Aplysia, changing motor neuron activity necessarily changes both $\mathrm{ACh}$ and peptide co-transmitter release.

Inputs from outside the network modulate the stomatogastric nervous system of decapod crustaceans. Approximately twenty neurotransmitters modulate the system (Marder, 2012). This multiplicity leads to a combinatorial explosion, with 20 ! $(2.4 \times$ 1018) possible combinations. Insect glomeruli similarly contain large numbers of peptide modulators (Neupert et al., 2012).

Vertebrate nervous systems have both these problems (Merighi, 2002; Sohn, 2015; Russo, 2017). First, many neurons release multiple transmitters that act through both ionotropic and metabotropic receptors. Second, at least 100 peptide neurotransmitters are present in vertebrate nervous systems, and individual neurons can receive multiple modulatory inputs. These data have led to an expectation that modulation will, in general, be complex.

Liessem et al. (2018) recently identified 65 neuropeptide gene transcripts in the stick insect, Carausius morosus. Stick insect locomotion has been intensively studied (Bässler, 1983; Gruhn et al., 2016; Bidaye et al., 2018; additional references in text). Stick insect leg muscles contract in response to ionotropic driving by glutamatergic excitatory motor neurons. Two dedicated systems (Pearson and Bergman, 1969; Hoyle et al., 1974), common inhibitor (CI) neurons, which release GABA and open $\mathrm{Cl}^{-}$channels (Wolf, 2014), and dorsal unpaired median (DUM) neurons, which release octopamine (Stolz, 2018) and act metabotropically, modify insect muscle activity. In the stick insect leg, individual DUM (Mentel et al., 2008) and CI (Debrodt and Bässler, 1989; Bässler et al., 1996; Bässler and Stein, 1996) neurons innervate functionally different muscle groups (Goldammer et al., 2012). This system seemed ideal for studying peptide modulation in a locomotory system.

To this end, we combined molecular biological approaches, the Liessem et al. (2018) inventory of potential stick insect neuropeptides, and muscle physiology to describe neuromodulation in the stick insect leg. We first labeled ganglia neurons by nerve backfills. We then removed individual filled somata and performed single-cell mass spectrometry (MS). This technique was sensitive enough to identify multiple peptides, and to identify the peptides each soma contained. We used immunohistochemistry to complement the spectrometry data on individual somata, and to identify peptides in the axons in nerves innervating the muscles. We chose a muscle well-enough described to easily perform physiological experiments on, described its peptide transmitter receptor inventory, and the effects on muscle activity of the peptide that is present in axons innervating the muscle and for which the muscle has receptors.
Excluding possible hemolymph-borne modulators, only one peptide, myoinhibitory peptide (MIP), contained in only CI and DUM, modulated all leg muscles. To our knowledge, this is the first unambiguous demonstration of a neuropeptide in CI and DUM. In the well-studied extensor tibiae (ExtTi) muscle, MIP reduced slow muscle fiber force and contraction amplitude, facilitating faster contraction and relaxation. Modulation in the stick insect leg is thus remarkably simple compared with other preparations. Only one neuronally-released peptide modulates the entire leg's musculature. The excitatory motor neurons not containing modulators means that muscle contraction amplitude can be altered without changing the modulator-set rapidity of muscle contraction and relaxation. Modulation thus exists on a continuum from simple (stick insect leg) to complex (Tritonia, Aplysia, stomatogastric system) in invertebrates. A similar continuum could exist in vertebrates.

\section{Materials and Methods \\ Animals}

Adult female C. morosus were used from a colony maintained at the University of Cologne. Animals were held in cages at $28^{\circ} \mathrm{C}$ with a $12 / 12$ $\mathrm{h}$ light/dark cycle and ad libitum access to blackberry leaves and water.

Synchrotron-radiation micro computed-tomography (SR- $\mu C T)$

The $3 \mathrm{D}$ anatomy of one C. morosus middle leg was imaged using SR$\mu \mathrm{CT}$ as described in Blanke et al. (2015). SR- $\mu$ CT was conducted at beamline PETRA III/IBL P05 operated by the Helmholtz Zentrum Geesthacht at the German Electron Synchrotron Accelerator (DESY; Beckmann et al., 2008) with a stable energy of $8 \mathrm{keV}$ in attenuation-contrast mode and a resolution of $1538 \times 1538$ pixels. Scan field of view ranged from the coxa-trochanter joint to two-thirds of the femur.

Image resolution was reduced with ImageJ (https://imagej.nih.gov/ ij). Structures were segmented in ITK-SNAP (Yushkevich et al., 2006; v. $3.8 \beta$ ) and exported as OBJ files. Final renderings, vertex reductions, and smoothing were performed using Autodesk Maya. 3D models are provided as an interactive 3D-PDF using DAZ Studio (v. 4.1 Pro, DAZ Productions) and as a video file. Nerves, muscles, and sense organs were named according to Marquardt (1939), Bässler (1983), and Graham (1985). Rendered animations were annotated using Adobe After Effects (CS6, Adobe Inc.).

\section{Tissue preparation for biochemical experiments}

For MS analysis and immunohistochemistry. Animals were cooled at $4^{\circ}$ $\mathrm{C}$ for $10 \mathrm{~min}$ and then fixed with dental cement (Protemp II, $3 \mathrm{M}$. Deutschland $\mathrm{GmbH}$ ) on a dissection plate. The body cavity or leg was opened and individual ganglia or muscles removed for further treatment. Throughout the dissection, the preparation was covered with chilled $\left(\sim 6^{\circ} \mathrm{C}\right)$ physiological saline (Weidler and Diecke, 1969$)$.

For Transcriptomic analysis. Legs were obtained by autotomy. ExtTi and flexor tibiae (FlxTi) muscles were dissected and immediately placed in RNAlater (Thermo Fisher Scientific).

\section{Single-cell MS}

Single-cell MS was performed as in Liessem et al. (2018). Briefly, cells were labeled with 5\% dextran-tetramethylrhodamine (MW 3000, anionic, lysine-fixable, Invitrogen) by retrograde backfills of lateral [nervus lateralis $2-5(n l 2-n l 5)$; nervus cruris $(n c r)$ ] and segmental [nervus anterior $(n a)$; nervus posterior $(n p)$; nervus transversus $(T N)$ ] nerves of prothoracic (T1), mesothoracic (T2), and metathoracic (T3) ganglia for $2 \mathrm{~d}$ at $4^{\circ} \mathrm{C}$. Labeled cells were dissected under a stereo fluorescence microscope (SteREO Lumar.V12, Carl Zeiss AG) and transferred with a glass capillary (Hilgenberg $\mathrm{GmbH}$ ) onto a sample plate for MALDI-TOF MS analysis. Cells were identified by cell body location and axonal projection based on data from T2 (Goldammer et al., 2012). Reference images of each dissected ganglion were taken from the ventral and dorsal side before it was desheathed and from the dissected cell on the MALDI sample plate. Residual saline was removed, samples were covered with $\sim 100$ 


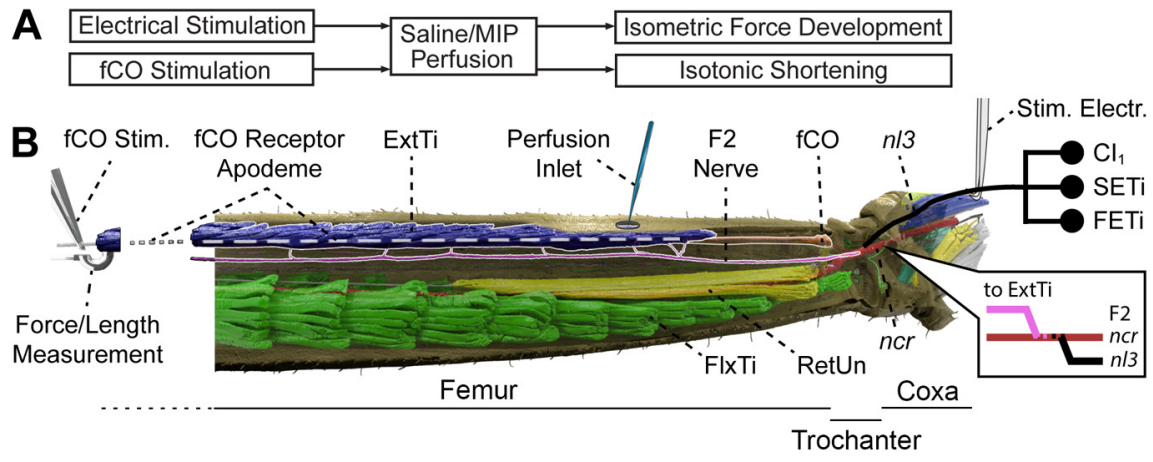

Figure 1. Experimental design and muscle anatomy and innervation. $A$, ExtTi responses were elicited by electrical stimulation of $n / 3$, which contains axons of $\mathrm{Cl}_{1}$ and slow (SETi) and fast (FETi) ExtTi excitatory motor neurons that reach nerve $\mathrm{F}_{2}$ via the $n c r$ (inset in $\boldsymbol{B}$ ), or sinusoidal fCO stimulation. ExtTi muscles were continuously and completely perfused with saline or saline with $10^{-6}$ M MIP- 6 through an inlet distal to the $\mathrm{fCO}$. Isometric force and isotonic shortening were measured. $\boldsymbol{B}, \mathrm{SR}-\mu \mathrm{CT}$ lateral view of the femur with cuticle virtually removed to reveal inner anatomy and innervation. Leg muscles color coded, motor neuron input in black. The ExtTi apodeme was attached to a hook to measure muscle responses. Coxa, trochanter and two-thirds of the femur indicated by solid lines. Dotted line shows distal third of femur. RetUn, retractor unguis muscle.

$\mathrm{nl}$ of $10 \mathrm{mg} / \mathrm{ml}$ 2,5-dihydroxybenzoic acid (Sigma-Aldrich) dissolved in $79 \% \mathrm{H}_{2} \mathrm{O}, 20 \%$ acetonitrile, $1 \%$ formic acid (v/v/v), and blow-dried.

Mass fingerprint spectra $\left(\mathrm{MS}^{1}\right)$ were acquired in positive ion mode with an ultrafleXtreme TOF/TOF mass spectrometer (Bruker Daltonik). MS acquisitions were made under manual control in reflector positive mode in a detection range of $\mathrm{m} / \mathrm{z} 600-10,000$. Instrument settings were optimized for mass ranges of $\mathrm{m} / \mathrm{z} 600-4000$ and 3000-10,000. Bruker peptide and protein standard kits were used for calibration (mass accuracy $1.4 \mathrm{ppm}$ ). Data were processed with flexAnalysis 3.4 (Bruker Daltonik). Tandem MS (MS ${ }^{2}$ ) experiments were performed with LIFT technology without CID or using an ABI 4800 proteomics analyzer (Applied Biosystems; Data Explorer v4.1) in gas-off mode. MS ${ }^{2}$ fragment spectra were acquired manually and peptide identities verified by comparison to theoretical (http://prospector.ucsf.edu) and experimentally obtained fragments.

\section{Immunohistochemistry and neural tracing}

Ganglia were desheathed with ultrafine scissors and parts of the leg cuticle removed to expose the ExtTi muscle and enhance antibody penetration. Tissues were fixed in $4 \%$ paraformaldehyde ( $\mathrm{pH}$ 7.4) or GPA [6.25\% glutaraldehyde, $75 \%$ picric acid, $5 \%$ glacial acetic acid in PBS $+1 \%$ Triton $\mathrm{X}-100$ (PBT); Merck] for $2 \mathrm{~h}$ at room temperature (RT; $20-22^{\circ} \mathrm{C}$ ) or overnight at $4^{\circ} \mathrm{C}$ and then rinsed overnight in PBT. GPA autofluorescence was reduced with sodium borohydride $(0.5 \%$ in PBS, $15 \mathrm{~min}$ ) followed by three 10 -min washes in PBS. Samples were dehydrated in an ascending ethanol series (50\%, 70\%, 90\%, 100\%, and $100 \%, 10 \mathrm{~min}$ each), cleared in Xylol (Merck) for $\sim 7 \mathrm{~min}$, rehydrated with the same ethanol series in reverse order, and washed three times in PBT for $10 \mathrm{~min}$. In most preparations, antibody penetration was enhanced by incubation in $0.1 \%$ Collagenase/Dispase (Roche) and $0.1 \%$ hyaloronidase (Sigma-Aldrich) at $37^{\circ} \mathrm{C}$ for $1 \mathrm{~h}$. Samples were preincubated for $2 \mathrm{~h}$ in PBT containing 5\% normal goat serum (NGS; Jackson ImmunoResearch).

Samples were then incubated with primary antiserum (1) polyclonal anti-MIP (anti-Periplaneta americana-MIP, GWQDLQGGWa, raised in rabbit, 1:500 in PBT + 1\% NGS; Predel et al., 2001), (2) anti-GABA (raised in rabbit, Sigma-Aldrich, 1:750 in PBT + 1\% NGS), or (3) antiSYNORF1 (aSynapsin, raised in mouse, Developmental Studies Hybridoma Bank, University of Iowa, IA, 1:75 in PBT $+1 \%$ NGS), all with $0.02 \%$ sodium azide to prevent fungal infection, for $4 \mathrm{~d}$ at $4^{\circ} \mathrm{C}$. Whole mounts were then rinsed three times for $2 \mathrm{~h}$ with PBT and incubated with either goat anti-rabbit antibody conjugated to Cy3 (Jackson ImmunoResearch, 1:2000 in PBT $+1 \%$ NGS) or goat anti-mouse IgG $(\mathrm{H}+\mathrm{L})$ Highly Cross-Adsorbed Secondary Antibody Alexa Fluor 633 $\left(1: 200\right.$ in PBT $+1 \%$ NGS, Thermo Fisher Scientific) for $4 \mathrm{~d}$ at $4^{\circ} \mathrm{C}$. In double labeling experiments, the samples were again preincubated in
PBT $+5 \%$ NGS for $2 \mathrm{~h}$ at RT, followed by incubation in the second primary and secondary antibodies as described above. All preparations were then rinsed overnight in $\mathrm{PBT}$ and mounted in glycerin/Mowiol (Hoechst AG/Calbiochem).

CI and DUM neurons were double labeled by backfills of lateral nerves with NEUROBIOTIN (2.5\% in distilled water, VECTOR Laboratories Inc) for $48 \mathrm{~h}$ at $4^{\circ} \mathrm{C}$. After fixation, clearing, and immunolabeling against MIP as described above, samples were washed twice in PBS at RT for $10 \mathrm{~min}$ each, preincubated with PBT $+5 \%$ NGS for $2-$ $3 \mathrm{~h}$, and incubated with Streptavidin (Strep) conjugated to Alexa Fluor 488 or 633 (1:600 in PBT $+1 \%$ NGS, Thermo Fisher Scientific) for $48 \mathrm{~h}$.

\section{Image acquisition}

Immunofluorescent labels were visualized with a confocal scanning microscope (Leica TCS SP8 LIAchroic) using the Leica Application Suite X (LAS X, Leica Microsystems) using HC PL APO $10 \times / 0.4$, HC PL APO $20 \times / 0.75$ IMM, or HC PL APO $63 \times / 1.2$ CORR objectives. Fluorophore signals were detected in serial stacks with a minimum resolution of $1024 \times 1024$ pixels using each dye's optimal laser line (488/552/638). Images were scanned sequentially to reduce dye cross-excitation.

\section{RNA extraction and sequencing}

Legs were dissected as described above. RNA was extracted from the ExtTi and FlxTi muscles of a single middle leg using TRIzol (Thermo Fisher Scientific) following manufacturer recommendations. RNA quality was estimated using RNA concentration (ng/ $\mu \mathrm{l})$ and RNA integrity number as implemented in Agilent 2100 Bioanalyzer. Libraries were prepared using $1-\mu \mathrm{g}$ total RNA with the Illumina TruSeq stranded RNA sample preparation kit. Poly A containing mRNA were purified using oligo-dT attached magnetic beads and then fragmented and primed for cDNA synthesis. Fragmented RNA was reverse transcribed using random hexamers to produce first strand cDNA; second strand cDNA was synthesized with DNA polymerase I and RNase H. After end repair and A-tailing, multiple indexing adapters for hybridization onto a flow cell were ligated. Products were enriched with PCR and purified to create the final cDNA library. Sequencing was done on an Illumina HiSeq 4000 Sequencer with 75 paired ends at Cologne Center for Genomics (CCG).

\section{De novo assembly of nucleotide sequences}

Raw data were filtered by removing low quality reads and adapters using Trimmomatic-0.38 (Bolger et al., 2014) and stored as FASTQ files. Transcripts were subsequently assembled de novo using Trinity 2.2.0 (Grabherr et al., 2011; Haas et al., 2013) and Bridger (v2014-12-01; Chang et al., 2015). Raw data and the Trinity assembly were submitted to NCBI [sequence read archives (SRA): SRR9134259; transcriptome shotgun assembly (TSA): GHMH00000000; BioProject: PRJNA543193].

\section{Neuropeptide precursor and receptor sequence compiling}

Database searches for $C$. morosus neuropeptide and protein precursor sequences were primarily conducted using the tBLASTn algorithm from the BLAST+ suite command-line tool (v2.4.0.; Camacho et al., 2009). Neuropeptide precursor sequences from C. morosus (Liessem et al., 2018) and neuropeptide receptor sequences of other insects (Hewes and Taghert, 2001; Hauser et al., 2006) were used as reference queries. Aligned and assigned nucleotide sequences were translated into protein sequences using the ExPASy translate tool (http://web.expasy.org/ translate/; Swiss Institute of Bioinformatics; Gasteiger et al., 2003). Precursor sequence signal peptides (SP) were predicted using SignalP 4.1 (http://www.cbs.dtu.dk/services/SignalP/, Technical University of Denmark, Denmark; Petersen et al., 2011). If no SP could be predicted or no stop 
Table 1. Overview of primers used for RT-PCR expression analysis in brain and ExtTi

\begin{tabular}{|c|c|c|c|c|}
\hline Gene & Gene abbr. & Forward primer $5^{\prime}-3^{\prime}$ & Reverse $5^{\prime}-3^{\prime}$ & Gene product length (bp) \\
\hline MIPR & MIPR_A & TTCTGGGCCTCATGCTGCTAGTG & CAAATGTCGACAACACAAGCACGTG & 531 \\
\hline MIPR & MIPR_B & ATGTTCACCCTGCTCTTCCC & CACTCGATGTCCAGCGGAAC & 329 \\
\hline MIPR & MIPR_C & AGTACGTTCCGCTGGACATC & ATCTCGACGAGCAGGAAGAC & 331 \\
\hline Actin & Actin & AGCTACGTAGGCGATGAAGC & CGATACCAGTGGTACGACCG & 301 \\
\hline GABA a receptor & GABA & TCCGACACAGACGAGAGCTA & GAAGAAGCCTGTGTGCCTCT & 534 \\
\hline Glutamate receptor (GluRIID-RA) & Glu & CCGGAAGAGTTGGAGAACCA & GGACTCCATGAGGAAGGCAT & 414 \\
\hline 0ctopamine receptor (0amb) & Octo $0 \mathrm{amb}$ & GACGACCCGTACCTGCTG & GATTCCGTCGGCTCGTACAC & 512 \\
\hline 0ctopamine receptor ( $\beta 2 \mathrm{r}$ ) & Octo $\beta 2 \mathrm{r}$ & TTCATGGGCTGGTACACGAC & GAAGGCTTCCCTGAAGTCCC & 597 \\
\hline Tyramine receptor (Tyr1A) & Tyr & TGCTCGTCATACTCAGCGTC & TCGCGATGAAGATCTCGACG & 501 \\
\hline
\end{tabular}

The primers were designed from the putative GPCR transcripts for MIP (MIPR), GABA, glutamate, octopamine, and tyramine. For MIPR, two primer sets were used (MIPR_a and MIPR_C). as a control, we used primers against actin.

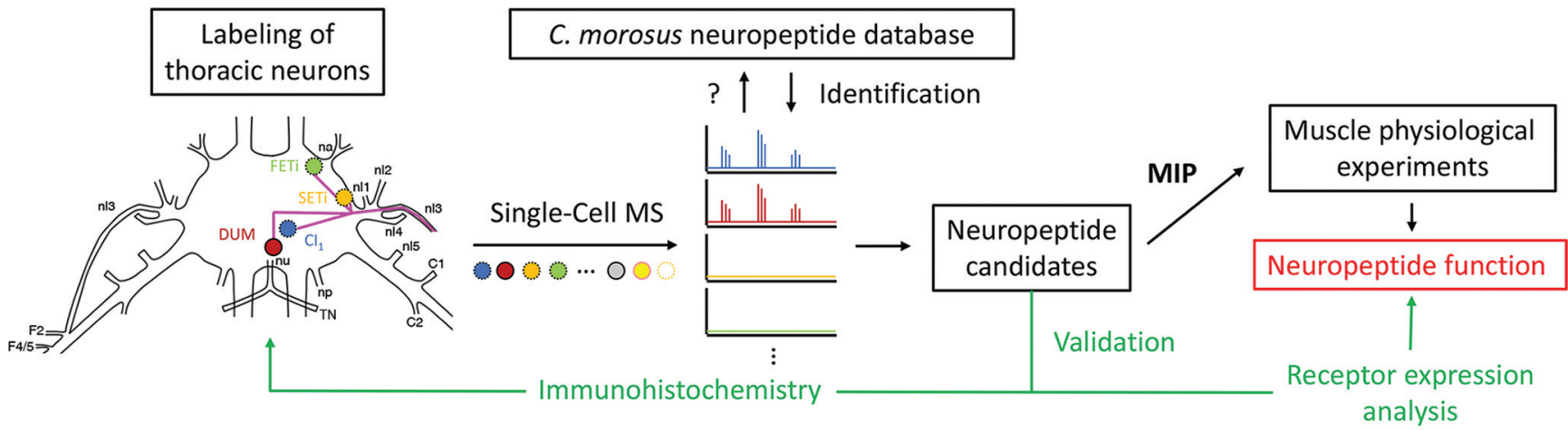

Figure 2. Molecular biological, immunohistochemical, and physiological methods used to describe stick insect leg neuromodulation. Leg nerves were backfilled to identify neurons (far left) with axons in the nerves Case shown is an n/3 backfill. DUM, $\mathrm{Cl}_{1}$, FETi, and SETi were filled. For clarity, some additional filled neurons not shown. Positions in ganglion are approximately correct. DUM (solid circle outline) is dorsal, other neurons (dashed circle outlines) ventral. Individual somata were removed and their neuropeptide inventory analyzed using single-cell MS based on the C. morosus neuropeptide inventory (Liessem et al., 2018; next panel going right; neuron colors in leftmost panel maintained; MS only schematic, signal positions placement arbitrary). $\mathrm{Cl}_{1}$ (blue) and DUM (red) contained MIP. FETi and SETi contained no peptides from inventory. Immunohistochemistry was used to examine whether somata staining was consistent with spectrometry data and to examine peptide presence in nerve processes running along ExtTi muscle. Transcriptomic and PCR analysis confirmed expression of MIPRs in ExtTi, but not receptors for any other peptide in ganglia somata (next panel going right). MIP effects on muscle contractions was then investigated (far right panel). nu, nervus unparis; $\mathrm{C1}_{-2}$, coxa branch $1-2$ of ncr; F4, and 5, femoral branches 4 , and 5 of ncr.

codon was present, precursors were considered incomplete. In these cases, we attempted to complete the precursors using the additional Bridger assembly or BLAST tool on the raw transcriptome data. In the latter case, the resulting transcripts were recursively used as an input query until they were considered complete (no further increase in transcript length, SP was predicted at the N-terminus, and/or in-frame stop codon was detected). Near complete receptor sequences were analyzed for G-protein-coupled receptor (GPCR) motifs using GPCRHMM (https://gpcrhmm.sbc.su.se; Wistrand et al., 2006).

Prediction of C. morosus MIP receptor (MIPR) sequence

The sequence was assembled from three transcriptome fragments (accession number: MT879357, MT879358, MT879356) and two fragments cloned/sequenced from cDNA (MIPR_A and MIPR_B).

MIPR_A was prepared from adult brain using ZR Tissue \& Insect RNA MicroPrep (Zymo) for total RNA preparation and Maxima First Strand cDNA Synthesis kit (Thermo Fisher Scientific) for cDNA synthesis. PCR was performed using the Phusion High-Fidelity PCR kit (New England Biolabs) for 30 cycles with an annealing temperature of $68^{\circ} \mathrm{C}$ and 1 min elongation (for primers, see Table 1 ). The PCR product was purified and cloned using the CloneJET PCR Cloning kit (Thermo Fisher Scientific, vector accession no.: EF694056) and confirmed by Sanger sequencing (Eurofins). MIPR_C is situated within MIPR_A (for primers, see Table 1).

MIPR_B was prepared from an adult muscle immediately put into RNAlater (Sigma-Aldrich) to protect RNA integrity. Total mRNA was extracted using the easy-spin Total RNA Extraction kit (iNtRON Biotechnology). Concentration was determined by measuring OD280/ 260. cDNA was synthesized using SuperScript II Reverse Transcriptase (Invitrogen). For RT-PCR the full length of MIPR_B was used.
Primers for other genes (see Table 1) were either designed from transcriptome sequences or conserved regions within multiple alignments of Drosophila melanogaster, Timema cristinae (GCA_002928295.1), and Lipaphis erysimi (MG993326.1) sequences. All PCR products were validated by sequencing.

\section{Muscle physiological experiments}

Animals were fixed dorsal side up with all legs except the right middle amputated. The coxa, trochanter, and femur were then covered with dental cement except two small windows at femur proximal and distal ends to allow access for a constant perfusion system, to the apodeme of the femoral chordotonal sense organ (fCO), and the ExtTi distal apodeme. T2 and the distal part of ExtTi were exposed and perfused with saline. ExtTi and FlxTi lengths at an FT angle of $90^{\circ}$ were defined as ExtTi and FlxTi rest lengths ("muscle reference length"; Friedrich, 1933; Storrer, 1976; Guschlbauer et al., 2007). Figure 1 shows a schematic of the preparation.

Experiments were performed under daylight conditions at RT. Isometric force and isotonic shortening amplitudes were measured. Two stimulation paradigms were used. In one, FETi, SETi, and CI $1\left(\mathrm{CI}_{1}\right)$ axons were simultaneously activated by $n l 3$ electrical stimulation (Guschlbauer et al., 2007). In the other, SETi and $\mathrm{CI}_{1}$ neuron activity alone was induced by fCO movement (Bässler and Stein, 1996). These two approaches allowed discriminating between MIP effects on the whole muscle and on muscle slow fibers alone.

In the first paradigm, $n l 3$ was pinched proximal to the electrode to isolate the muscle from T2 neuron activity and stimulated electrically with current pulses applied to a bipolar stainless-steel electrode isolated with petroleum jelly (Korasilon-Paste, Kurt Obermeier GmbH \& Co $\mathrm{KG})$. The fCO apodeme was cut and other lateral nerves pinched. Nerve 

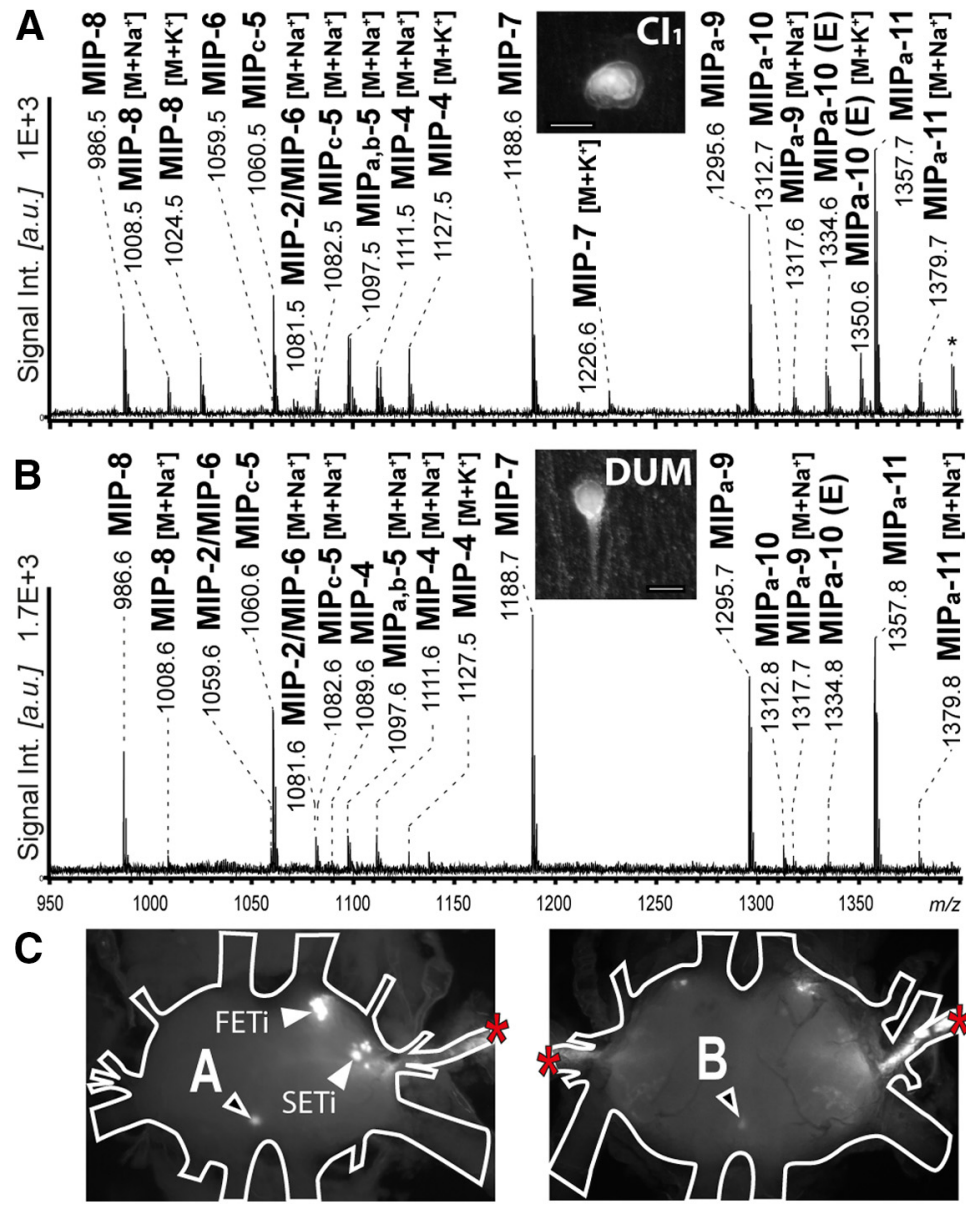

Figure 3. MALDI-TOF mass spectra from single $\mathrm{Cl}_{1}$ (soma marked $\mathrm{A}$ in panel $\boldsymbol{C}$, left) and DUM (soma marked $B$ in panel $\boldsymbol{C}$, right) neurons. Cells visualized by backfilling one (panel $\boldsymbol{C}$, left, ventral side up) or two (panel $\boldsymbol{C}$, right, dorsal side up) $n / 3 . n / 3$ contains the axon of only one DUM neuron (Goldammer et al., 2012), which bifurcates before leaving the ganglion. That only one soma backfilled in panel $C$, right, shows that the neuron is a DUM. $A, B$, Single-cell mass spectra of $\mathrm{Cl}_{1}$ and DUM neurons, respectively. All peaks corresponded to MIP peptides (that is, no other peptides were found in the neurons); numbers in names indicate which of the 11 MIP peptides the peak corresponds to. The Arg-containing MIPs 5, 7-9, and 11 ionize better than the other MIPs (Liessem et al., 2018) and therefore generally have higher signal intensity in MALDI-TOF mass spectra. Bracketed text shows salt adducts. Titles without brackets are single charged peptide products $\left([\mathrm{M}+\mathrm{H}]^{+}\right)$. Uncapitalized letters following MIP in same labels indicate that peptides are from different MIP transcripts. Insets, $\mathrm{Cl}_{1}$ and DUM after dissection. Inset scale bars: $50 \mu \mathrm{m}$. $C$, Schematic of T2 ganglion and associated nerves (outline) and picture of ganglia and labeled cells ( $\boldsymbol{A}, \boldsymbol{B}$, arrowheads) before removal. Red asterisks mark backfilled nerves. In left panel, filled DUM soma cannot be seen because it is located on the ganglion's dorsal side. In right panel, filled $\mathrm{Cl}_{1}$, FETi, and SETi somata cannot be seen because they are located on the ganglion's ventral side.

stimulations and muscle contractions were triggered and recorded with Spike2 (version 7.2, Cambridge Electronic Design). Six current pulses (duration $0.5 \mathrm{~ms}, 40 \mathrm{~Hz}$ ) were generated by a Universal Digital Stimulator (model MS 501) and stimulation isolation unit (SIU). Stimulator, SIU, and bipolar electrode were built by the University of Cologne Animal Physiology Electronics Workshop. To minimize muscle fatigue, the time between each pulse series was $60 \mathrm{~s}$. At the beginning of each experiment, pulse amplitude was increased until further increase caused no additional change in force, which was taken as an indicator that SETi, FETi, and $\mathrm{CI}_{1}$ were all stimulated. Pulse amplitude was then set 2.5-fold higher to ensure consistent stimulation.

In the second, the $\mathrm{fCO}$ was activated to measure muscle response to SETi and $\mathrm{CI}_{1}$ activity alone. This cannot be accomplished by electrical stimulation because FETi axon diameter is greater than SETi and $\mathrm{CI}_{1}$ axon diameters (Bässler and Storrer, 1980). FETi therefore activates at lower current amplitudes. fCO movement activates all three neurons, but FETi responses cease within a few cycles of repetitive stimulation (Kittmann, 1997). The fCO apodeme was cut and mounted according to Bässler (1983). The fCO was activated with $200-\mu \mathrm{m}, 0.1-\mathrm{Hz}$ sinusoidal movements about the $90^{\circ} \mathrm{FT}$ joint position, corresponding to $40^{\circ}$ joint movement (Weiland et al., 1986). fCO elongation mimics FT joint flexion; fCO shortening, joint extension. Stimulus duration was $50 \mathrm{~s}$. Interstimulus interval was $60 \mathrm{~s}$ to minimize muscle fatigue and fCO habituation (Kittmann, 1991, 1997). Muscle activation by the $\mathrm{fCO}$ requires that $n l 3$ be intact. Bipolar electrodes were placed on $n l 3$ to monitor SETi, FETi, and $\mathrm{CI}_{1}$ activity and either $n l 2$ or $n l 5$, both of which carry $\mathrm{CI}_{1}$ axon branches, to identify $\mathrm{CI}_{1}$ action potentials on both $n l 3$ and either $n l 2$ or $n l 5$. All other lateral nerves were pinched. $\mathrm{CI}_{1}$ activity was identified by recording from $n l 3$ while stimulating $n l 2$ or $n l 5$ and vice versa. Signals were recorded at $10 \mathrm{kHz}$ (high-cut filter $5 \mathrm{kHz}$, low-cut filter $60 \mathrm{~Hz}$ for $n l 3,65 \mathrm{~Hz}$ for $n l 2 / n l 5)$ and amplified 1000 -fold.

$\mathrm{CI}_{1}$ and possible DUM co-activation in these paradigms needs to be addressed. DUMETi axon diameter is very small in locust hindleg (Hoyle, 1978). This is probably also true for stick insect thorax desDUM neurons because it is essentially impossible to distinguish DUM spikes from noise in connective extracellular recordings (Stolz, 2018). We therefore cannot know whether our protocols activated DUM neurons. However, fCO responses are weak in stick insect desDUM neurons (Stolz et al., 2019) and, in locust, only two of 30 thoracic DUM (Field et al., 2008) neurons responded, and the responses were "weak" and "inconsistent." Regardless, that MIP altered muscle contractions in both protocols indicates that whatever DUM activation may have occurred was insufficient to affect the conclusions presented here. Both protocols unavoidably induced some $\mathrm{CI}_{1}$ activation. $\mathrm{CI}_{1}$ may consequently have been releasing MIP, and the muscles thus experiencing some level of MIP action even in saline. Muscle control activities may therefore be less than what SETi and FETi activity alone would produce. In this case, MIP application would reduce muscle activity from an already slightly decreased base level. MIP's effects may thus be larger than that shown in the Results.

Muscle contraction was measured with a force (resolution, $0.3 \mathrm{mN}$ ) and movement (resolution, $1 \mu \mathrm{m}$ ) transducer (ALS, Aurora 300 B dual-mode lever system; Aurora Scientific Inc.). The animal was dissected as described above and a hookshaped insect pin, connected to the lever arm of the ALS, was pierced through the cut end of the ExtTi apodeme (Guschlbauer et al., 2007). The ALS allows setting a maximum force level below which the apparatus holds muscle length constant. Isometric contractions were measured by setting this level high enough to prevent muscle shortening for all motor neuron stimulations. Isotonic contractions were measured by reducing the ALS maximum force level. The values chosen resulted in shortenings approximately in the muscle's physiological range (100 to $\sim 400 \mu \mathrm{m}$; Guschlbauer et al., 2007). Because of interanimal variability (Blümel et al., 2012a; Guschlbauer et al., 2007), this value was set individually for each animal. Muscle reference length was always determined before the ExtTi apodeme was cut. ALS zero force was set with the insect pin resting on the distal femur without the muscle attached. Analog signals were digitized using a Micro1401 CED (sampling rate for length and force, $10 \mathrm{kHz}$ ) and viewed and analyzed using Spike2. 
The proximal part of the femur was impaled with a small glass capillary coupled to a perfusion system (Alitea UD-Midi-D. Peristaltic Pump; Fig. 1) to allow constant perfusion of the muscle with saline (RT, aerated with an aquarium bubbler) or saline containing $10^{-6}$ м MIP (C. morosus MIP6, AWQDLQGGWa, synthesized by GenScript). This concentration was chosen because of the lower effective concentration of peptides versus small chemical neurotransmitters (Hooper and Marder, 1984; Marder and Hooper, 1985; Marder et al., 1987) and is a fairly standard concentration when checking for peptide effects (Hooper and Marder, 1984; Marder and Hooper, 1985; Marder et al., 1987; Schmidt et al., 1995; Kwok and Orchard, 2002). To ensure the perfusate flowed distally through the femur, the capillary tip was sealed to the surrounding tissues with dental cement and the body cavity filled with petroleum jelly. To determine when the drug perfused the muscle and to monitor whether the perfusate was entering the body cavity, fast green FCF (FG; Sigma-Aldrich) was added at low concentration to one or the other of the solutions.

To test for MIP effects on passive muscle force, ExtTi length was changed with a step pyramid of Spike2 Sequencer-generated ramp-and-hold stimuli from muscle reference length to 125,250 , and $125 \mu \mathrm{m}$ and back to muscle reference length. Ramp velocity was $500 \mu \mathrm{m} / \mathrm{s}$. Interramp hold duration was $10 \mathrm{~s}$. Interpyramid interval was $60 \mathrm{~s}$. Force traces were smoothed with a time constant of $0.001 \mathrm{~s}$. Single and mean force traces of five individual stimulations per condition were plotted as an overdraw.

\section{Muscle data acquisition and statistical analysis}

At rest length, unstimulated muscles produced a few $\mathrm{mN}$ of passive force. This force was subtracted from total force produced by the stimulations to obtain active force. Active force and shortening amplitudes were determined manually for each stimulus within a stimulation cycle and by averaging over the complete stimulus duration.

In the $\mathrm{fCO}$ experiments, mean $\mathrm{SETi}$ and $\mathrm{CI}_{1}$ firing frequencies were calculated in Spike2 (time width $1 \mathrm{~s}$ ). Early stimulation responses with FETi firing were discarded. Three to six subsequent stimulations were analyzed in different experiments. However, in each experiment, the same number of stimulations were analyzed in both saline and MIP. The first stimulus following MIP application was always excluded because muscle response had not stabilized. SETi firing frequencies decreased cycle by cycle. It was therefore necessary to find fCO stimulations with matched SETi and $\mathrm{CI}_{1}$ firing frequencies in both saline and MIP. In all experiments, these were the last stimulation in the saline trial before MIP application and the second stimulation after application.

Motor neuron activity was constant when $n l 3$ was stimulated electrically. In these experiments as many muscle responses in saline were compared with as many muscle responses in MIP as possible. This allowed us to exclude additional trials after MIP application (that is, first measurements were taken two or three trials after MIP application) in these experiments to ensure that muscle responses had stabilized. In each experiment, the same number of subsequent stimulations (three to six) were analyzed in both saline and MIP.

Statistical tests were performed in GraphPad Prism (paired and unpaired Student's $t$ tests) with an $\alpha$ level of $p<0.05$ (key for significance: $\left.{ }^{*} 0.01<p<0.05,{ }^{* *} 0.001<p \leq 0.01,{ }^{* *} p \leq 0.001\right)$. For data on which multiple comparisons were made, one-way ANOVA with Bonferroni corrected significance levels were conducted. Muscle responses were normalized by dividing each value in the experimental group by the mean of the corresponding control group. The data are presented as mean \pm SD.

\section{Data availability}

SRA and TSA data were uploaded to NCBI. Protein sequences were annotated and submitted to GenBank (https://www.ncbi.nlm.nih.gov/ genbank/).

\section{Results}

Given the prior work described in the Introduction, we expected that a complex modulatory system would regulate leg function. The Aplysia data suggested that leg excitatory motor neurons could have peptide co-transmitters. The Tritonia data suggested the muscles, in addition to ionotropic glutamate receptors, could have glutamatergic metabotropic receptors, with the excitatory motor neurons thus both causing and modulating contraction. The stomatogastric data suggested that different CI and DUM neurons could contain different neuropeptides. We therefore devised a set of experiments appropriate for investigating all these possibilities. Figure 2 schematizes our experimental plan. 


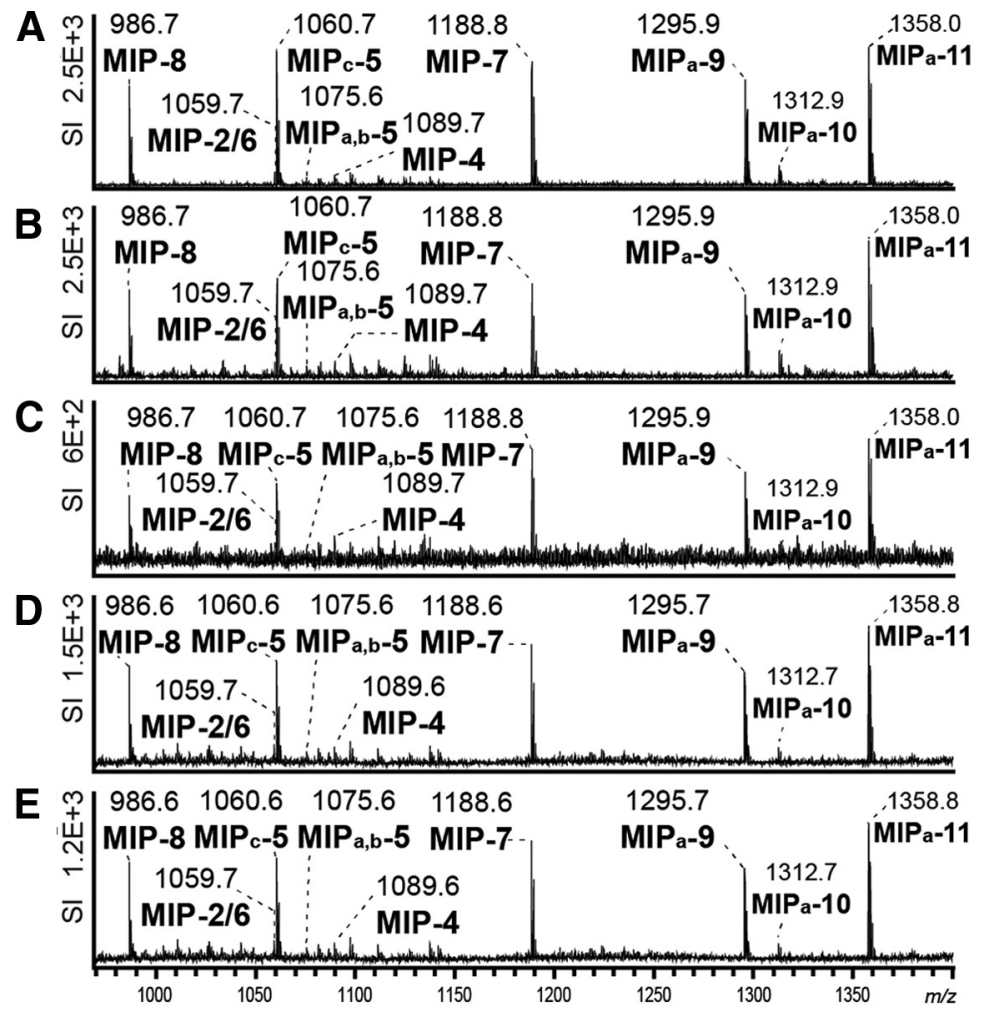

$\mathbf{F}$

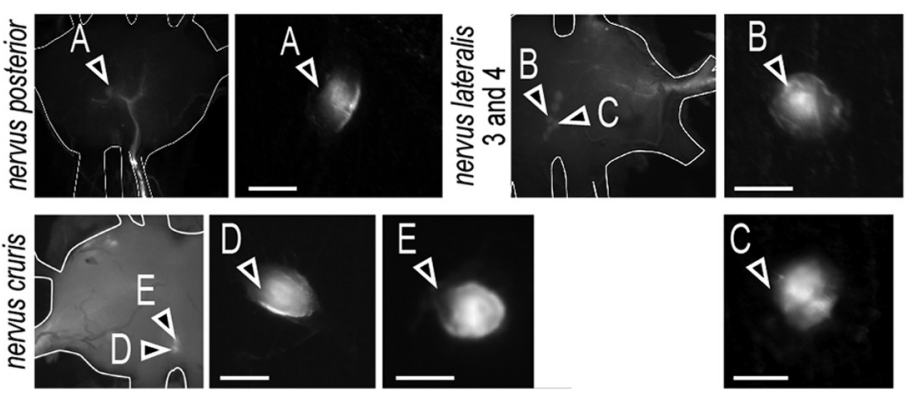

Figure 5. Representative MALDI-TOF mass spectra from single DUM neurons. Neurons visualized by $(\boldsymbol{A})$ backfilling $n p$ of ganglion $\mathrm{T} 1,(\boldsymbol{B}, \boldsymbol{C})$ simultaneously backfilling $n / 3$ and $n / 4$ of ganglion $\mathrm{T} 2$, and $(\boldsymbol{D}, \boldsymbol{E})$ backfilling $n c r$ of ganglion $\mathrm{T}$. The spectra exclusively contain MIP ion signals. All marked ion signals represent single charged peptide products $\left([\mathrm{M}+\mathrm{H}]^{+}\right)$. Sodium and potassium adduct ions of labeled neuropeptides and precursor peptides are not labeled. Uncapitalized letters following MIP in same labels indicate that peptides are from different MIP transcripts. SI, signal intensity. $\boldsymbol{F}$, Reference image of backfilled T1-T3 and overview of cells dissected in $\boldsymbol{A}-\boldsymbol{E}$, arrowheads. Scale bar: $50 \mu \mathrm{m}$.

Single-cell MS profiling showed many peptides in thoracic ganglion somata, but none in leg excitatory motor neurons, and only MIP in CI and DUM neurons

A total of 112 backfills were performed on thoracic ganglia (T1, $n=33$; T2, $n=54 ; \mathrm{T} 3, n=25)$ via the lateral and segmental nerves. Prior work on the axonal projection patterns and somata locations of T2 ganglion neurons (Goldammer et al., 2012) shows that the backfilled somata were DUM or CI neurons, excitatory motor neurons innervating leg or other muscles, or (rarely) sensory neurons. Backfills of homologous T1 and T3 ganglia nerves showed only minor differences in labeled cell numbers and positions. These data allowed identifying the leg muscle excitatory motor neurons and CI and DUM neurons among the 543 backfilled cells (176 in T1, 272 in T2, 95 in T3). In some cases, cells could only be identified as members of a cell population (e.g., the $\sim 25$ FlxTi muscle excitatory motor neurons). Because some sensory neurons have their somata in the thoracic ganglia, we cannot refer to backfilled neurons as efferent neurons, instead simply calling them backfilled neurons or neurons with axons in ganglia nerves.

The 543 backfilled neurons showed neuropeptide processing from the allatostatin A (AstA), allatostatin CC (AstCC), elevenin, extended FMRFamides (FMRFa), MIP, myosuppressin, neuropeptide-like precursor 1 (NPLP1), and orcokinin A (OK-A) precursors. These peptides were detected in neurons innervating targets other than leg muscles. For example, backfills of the transversal nerve $(T N)$, which does not innervate the leg muscles (Goldammer et al., 2012), showed processing of FMRFa in posterolateral cells in all three thoracic ganglia, a result expected from work in stick (Liessem et al., 2018) and other (Predel et al., 2004; Wegener et al., 2006) insects. Of the neurons innervating leg muscles, alternatively, only the CI and DUM neurons contained neuropeptides.

DUM and CI neurons in individual ganglia can be differentially visualized by backfilling different nerves. For example, Figure 3 shows single-cell spectra (Fig. $3 A$ ) and backfill labeling (Fig. $3 C$ ) of a T2 $\mathrm{CI}_{1}$ backfilled via one $n l 3$, and a T2 DUM backfilled via both nl3 (Fig. $3 B, C)$. Both single-cell spectra had ion signals only from MIP peptides. In the combined data from all our backfill experiments, all CI $(n=32)$ and DUM $(n=46)$ neurons contained MIP, and only MIP (Figs. 4, 5). MIP ion intensity was generally higher in DUM than in CI neurons. Neurons in close proximity to CI that were removed for single-cell MS did not contain MIP or any other peptide (Fig. 6), indicating that, in general, we could remove neurons without contamination from nearby neurons.

We used the Goldammer et al. (2012) data to identify a large number of backfilled leg muscle excitatory motor neurons. Figure 3C, left panel, shows several backfilled neurons in the antero-lateral region of the ganglion. Two of these are the ExtTi excitatory motor neurons, SETi and FETi (white arrowheads). SETi $(n=7)$ and FETi $(n=10)$ single-cell spectra never had ion signals corresponding to $C$. morosus neuropeptides inventoried by Liessem et al. (2018; data not shown). Another example of a backfilled excitatory motor neuron, the depressor trochanteris muscle fast motor neuron, is shown below (Fig. 7G).

Of 160 identified leg muscle excitatory motor neurons $(63 \mathrm{nl} 3$ backfills, $36 \mathrm{ncr}, 4 \mathrm{nl5}, 57 \mathrm{nl}$ ), only two contained peptides, in both cases MIP. Given the high sensitivity of MS, a likely explanation for these MIP positive leg muscle excitatory motor neurons is contamination by adherent tissue. Even if not, these data would show that MIP is only very rarely present in leg muscle excitatory motor neurons $(2 / 160=1.3 \%)$.

Anti-MIP immunohistochemistry also showed that MIP was absent in leg excitatory motor neurons but present in $\mathrm{CI}$ and DUM neurons

MS has the advantage that, in most cases, one can measure a neuron's entire peptide inventory in a single experiment. It also 
has high sensitivity yet (as long as no adherent tissue is taken) very small likelihood of false positives. Single-cell MS is therefore the gold standard for peptide presence and absence in neurons. However, although we performed MS on a large number of single cells, the effort required limits the number of cells that can be examined. Immunohistochemistry has increased likelihood of both false positive and negatives, but allows examining large numbers of cells for antigen presence and absence. We therefore complemented single-cell MS with immunohistochemistry using an MIP antiserum.

MIP immunoreactivity was consistently observed in $8-10$ dorsal median neurons and three paired neurons on the ventral side of T1-T3 (Fig. $7 A, E)$. Neuron size, arrangement, location, and axonal projection correspond to those of C. morosus DUM and CI neurons (Goldammer et al., 2012). Staining was typically less in CI than DUM neurons, consistent with the MS. Immunoreactive axons in the nerves in which CIs and DUM neurons send their axons (na, nl2, nl3, ncr, and $n l 5$; Goldammer et al., 2012) were also observed (data not shown).

In some experiments, DUM and CI identity were confirmed with combined backfill and MIP staining. Figure $7 B, C$ shows examples for the $\mathrm{CI}$ neurons: $\mathrm{CI}_{1}$, located slightly contralateral to the leg it innervates near the ganglion midline; $\mathrm{CI}_{2}$, more anterior and ipsilateral of the midline; and $\mathrm{CI}_{3}$, more posterior and lateral near the posterior nerve roots. In Figure $7 C$, the stained cell adjacent to the stained and backfilled $\mathrm{CI}_{1}$ is presumably the contralateral $\mathrm{CI}_{1}$. This is good evidence of the MIP immunoreactivity because the contralateral nerves were not backfilled. Figure $7 E-G$ shows an example for the DUM neurons.

GABA presence in C. morosus CI's has not been investigated before with immunohistochemistry. Staining with GABA antiserum show three pairs of cells on the ventral side whose morphologies correspond to CI morphologies (Fig. 8). Since both MIP and $\mathrm{GABA}$ antibodies were raised in rabbit, double labeling experiments could not be performed.

In almost all MIP staining experiments, cells identified as leg muscle excitatory motor neurons did not stain. For example, Figure $7 G$ shows an unstained neuron backfilled via the $n c r$ nerve with the position and projection pattern of the depressor trochanteris muscle fast motor neuron (see Goldammer et al., 2012). For completeness, we show here the one case in which possible leg muscle excitatory motor neurons stained (Fig. $7 D$ ). This occurred in the antero-lateral portion of the ganglia containing FETi, SETi, and $\sim 25$ FlxTi muscle excitatory motor neurons. In the experiment shown, four cells in this region stained (arrowheads), three of which had also backfilled (white arrowheads). Given the very low detection rate of MIP in leg excitatory motor neurons observed with MS, we believe this one example of MIP immunostaining of possibly excitatory motor neurons is a false positive. Even if not, the MS and immunohistochemistry data would indicate that MIP co-expression in leg motor neurons occurs only very rarely.

In summary, MS and immunohistochemistry showed that CI and DUM neurons contained MIP and leg muscle excitatory motor neurons either did not, or did so only very rarely. The ability of the single-cell MS to detect a large variety of other peptides in other neurons shows that, if these peptides were in CI,
DUM, or leg muscle excitatory motor neurons, the technique would have detected them. Similarly, the ability of the single-cell MS to detect MIP in CI and DUM shows that, if MIP was in leg muscle excitatory motor neurons, the technique would have detected it. Thus, we have demonstrated the presence of MIP, and only MIP, in the pathways (CI, DUM) known to regulate the leg muscles, and the absence of MIP, and of the other 140 possible neuropeptides encoded by the neuropeptide gene transcripts in C. morosus, in the excitatory leg motor neurons.

ExtTi muscle expresses receptors for several peptides but, of peptides present in ganglia neurons with axons in ganglia nerves, only for MIP

In a complete description of leg muscle control, the next step would be to inventory the peptide receptors of all leg muscles. Such an effort is beyond the scope of the present work. The experimental techniques for working with the ExtTi muscle are very well developed, and a large amount of information is known about its properties in control saline (Guschlbauer et al., 2007; Hooper et al., 2007; Blümel et al., 2012b; Godlewska-Hammel et al., 2017). We therefore chose to work on the ExtTi muscle. The ExtTi muscle is innervated by FETi, SETi, and three DUM neurons, and is one of the group of leg muscles inhibited by $\mathrm{CI}_{1}$ (Goldammer et al., 2012).

\section{Right middle leg inner anatomy}

Existing descriptions of C. morosus ExtTi muscle anatomy and innervation (Bässler et al., 1996) do not have the level of detail and completeness available with modern techniques (e.g., SR$\mu \mathrm{CT})$. Moreover, the innervation pattern of the F2 nerve onto the muscle was never fully described (Bässler and Storrer, 1980; Bässler, 1983). To better describe this innervation, and to compare it with our immunohistochemical results, we used neural

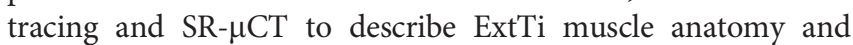
innervation in the intact leg. In the SR- $\mu \mathrm{CT}$ work 35-leg structures were labeled, including the $\mathrm{F} 2$ nerve. The $3 \mathrm{D}$ reconstruction can be viewed as a 3D-PDF (3D Model 1) or high-quality rendered video file (Movie 1). 


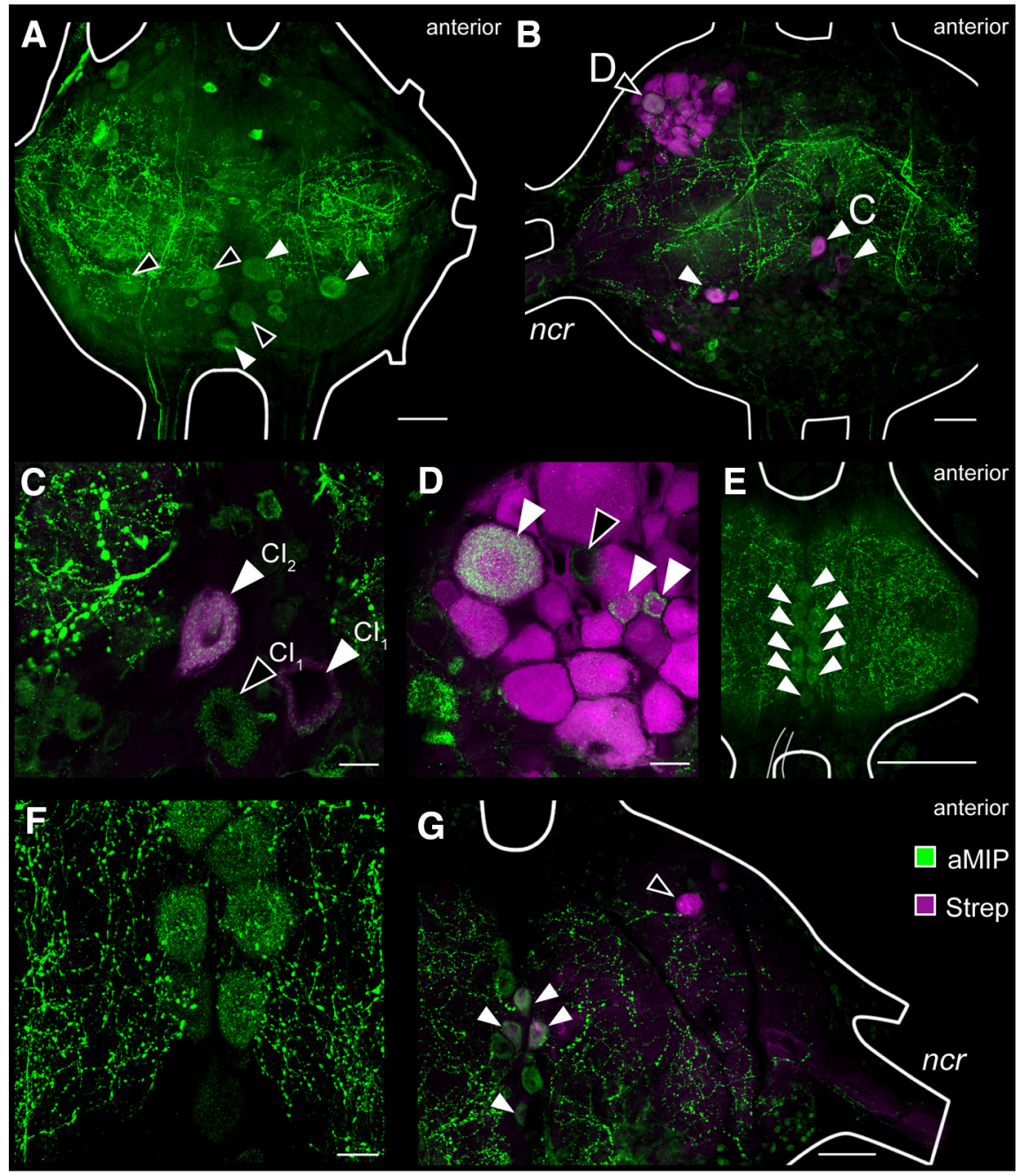

Figure 7. Immunohistochemical confirmation of MIP in $\mathrm{Cl}$ and DUM neurons and limited or no staining of leg muscle motor neurons. A, MIP immunoreactivity (green) in all three pairs of Cl neurons in T2 (white, black arrowheads). Scale bar: $100 \mu \mathrm{m}$. B, Cl identity confirmed by retrograde fill (magenta) of T3 $n c r$ and anti-MIP staining (colocalization, white arrowheads). Scale bar: $100 \mu \mathrm{m}$. $C$ Magnification of region labeled $\boldsymbol{C}$ in $\boldsymbol{B}$ showing MIP presence in two double labeled Cls (white arrowheads) and in another neuron, presumably the $\mathrm{Cl}$ of the contralateral side that was not backfilled (black arrowhead). Scale bar: $25 \mu \mathrm{m}$. $\boldsymbol{D}$, Magnification of region labeled $D$ in $\boldsymbol{B}$ (black arrowhead) of one case where MIP staining occurred in the antero-lateral motor neuron pool (arrowheads). Three of the neurons were also backfilled (white arrowheads), one was not (black arrowhead). Scale bar: $100 \mu \mathrm{m}$. $\boldsymbol{E}$, MIP immunoreactivity (green) in ten T2 DUM neurons. Scale bar: $250 \mu \mathrm{m}$. $\boldsymbol{F}$, Magnification of a region in $\boldsymbol{E}$ containing posterior DUM neurons. Scale bar: $25 \mu \mathrm{m}$. G, MIP in at least four T3 DUM neurons backilled via $n c r$ (colocalization, white arrowheads). Another neuron, presumably the fast depressor trochanteris muscle motor neuron (see Goldammer et al., 2012), was not labeled (black arrowhead). Scale bar: $100 \mu \mathrm{m}$.

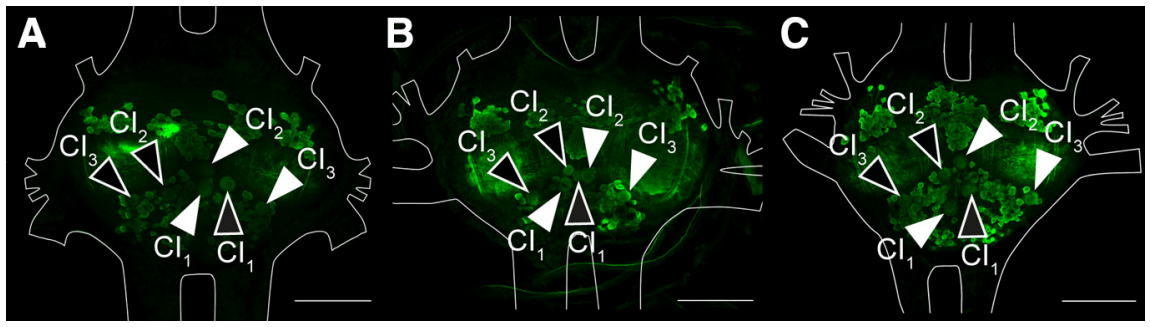

Figure 8. GABA immunoreactivity (green) in $(\boldsymbol{A}) \mathrm{T} 1,(\boldsymbol{B}) \mathrm{T} 2$, and $(\boldsymbol{C}) \mathrm{T} 3$ ganglia. Neurons identified as $\mathrm{Cl}$ neurons $1-3$ based on size and location. Animal-to-animal variation in position was greater in $\mathrm{Cl}_{1}$ and $\mathrm{Cl}_{2}$ than $\mathrm{Cl}_{3}$. Scale bar: $250 \mu \mathrm{m}$.

Fine anatomy of ExtTi and FlxTi and innervation of ExtTi muscle

Anterograde fills of $n l 3$ showed that $n l 3$ fuses with the $n c r$ nerve, from which nerve F2 branches more distally (Fig. 9A; see also
Fig. $1 B$, inset). F2 is located in the femur parallel to the main trachea and branches off to ExtTi when the main trachea does. It then splits and runs along the muscle in a modular organized fashion along the proximal distal axis with only minor overlap of its branches (Fig. 9B). Figure $9 C, D$ shows that the ExtTi muscle, tracheae, and $\mathrm{F} 2$ nerve reconstruction in $3 \mathrm{D}$ model 1 and Movie 1 are very similar to the anatomy shown by the anterograde nl3 fills.

Immunohistochemical analysis of the leg muscles using MIP antiserum confirmed (1) the presence of MIP varicosities on the ExtTi, FlxTi, and retractor unguis (RetUn) muscles, (2) axonal projections to and on the ExtTi muscle corresponding to those of the F2 nerve, and (3) colocalization of MIP and the presynaptic zone marker Synapsin in some of these varicosities. Figure $9 E$ shows immunoreactive fibers on the surfaces of the ExtTi and RetUn muscles. Except for the most proximal region, ExtTi was covered with a dense network of finely dividing processes with numerous varicositylike structures dispersed along their lengths. The axonal projection/innervation pattern of the anti-MIP staining (Fig. 9F) and the backfill-labeled (Fig. 9B) F2 nerve reconstructions (Fig. 9D) are very similar, suggesting ExtTi is supplied with MIP via axons located in the F2 nerve.

To investigate whether MIP is present in presynaptic sites, double-labeling with antisera against MIP and Synapsin was conducted (Fig. 9G). These experiments showed small $(1-3 \mu \mathrm{m})$ beaded structures immunoreactive to MIP, larger $(1.5-8 \mu \mathrm{m}$, the largest presumably being NMJs) presynaptic sites labeled with anti-Synapsin, and co-labeled 2- to 3.5$\mu \mathrm{m}$ synaptic boutons. These data suggest that MIP is present in both synaptic and non-synaptic sites, and is colocalized with classical transmitters in presynaptic sites on ExtTi muscle fibers.

\section{ExtTi transcriptome and expression analysis}

For MIP to alter muscle function, the muscle must express a MIPR. We therefore generated and analyzed ExtTi muscle transcriptomes. We used this dataset, and one publicly available from the $C$. morosus central nervous system (Liessem et al., 2018), to predict C. morosus neuropeptide and neurotransmitter receptor sequences based on similarities to corresponding sequences from other insects. Raw data and assemblies were uploaded to NCBI (BioProjectID: PRJNA543193). Accession numbers, including 


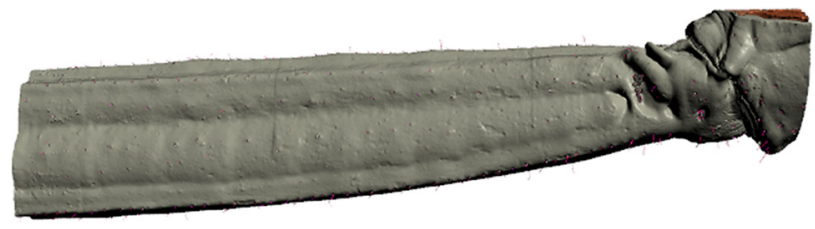

Model 1. SR- $\mu \mathrm{CT}$ reconstruction of intact right middle leg inner anatomy. Color key: beige, muscles; red, nerves; magenta, sensory structures; blue, diaphragm and tracheae. Point of view and visibility of structures can be altered manually or by using predefined views. For scale, cubes with 100 and $500 \mu \mathrm{m}$ edge lengths have been added. [View online]

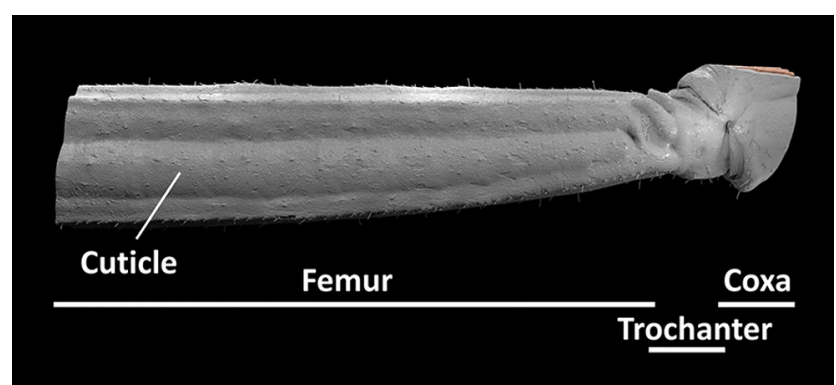

Movie 1. Annotated $360^{\circ}$ spin along the longitudinal axis of the femur from the reconstructed right middle leg. Same color key as in 3D model 1. BF, bristle field; CS, campaniform sensilla; F3, F121, F122, F3, F121, F122 nerves. [View online]

that of the MIPR, are listed in Tables 2, 3. Sahbaz and Iyison (2019) recently investigated C. morosus GPCRs. However, comparison is not possible, since no raw data, assemblies, or primer sequences were uploaded and most of the receptor sequences have not been made available.

Partial sequences of the predicted MIPR were found in both leg muscle and CNS transcriptomes (Fig. 10). Successful amplification from cDNA with a mixed muscle/CNS primer set (MIPR_A) confirmed CNS and muscle sequences belonging to the same gene (Fig. 10). A remaining gap in the prediction was closed by amplification from both CNS and muscle cDNA with gap-spanning primers (MIPR_B; see Fig. 10). The resulting amino acid sequence is highly similar to the orthologous receptor of Zootermopsis nevadensis (81\% identity, 89\% similarity, accession: XP_021921718.1) and appears complete, except for part of the signal sequence (Fig. 10). Searches for conventional neurotransmitter receptors in the leg transcriptome found sequences for the $\mathrm{GABA}_{\mathrm{A}}$ receptor (GABAaR), glutamate ionotropic receptor (GluR), and nicotinic ACh receptors but not for the octopaminergic $\mathrm{Oamb}$ and $\operatorname{Oct} \beta 2(\operatorname{Oct} \beta 2 \mathrm{R})$ receptors or the tyraminergic Tyr1A receptor (Fig. $11 C$, plus, minus signs in ExtTi column). Transcripts for all these receptors were found in the CNS (Fig. 11C, plus signs in brain column; Tables 2, 3). We validated these data with RT-PCR on CNS (Fig. 11A) and muscle (Fig. 11B). This analysis found GABAaR, GluR, MIPR, and Oct $\beta 2 \mathrm{R}$ in the muscle (Fig. $11 C$, green in ExtTi column). MIPR was present in both the proximal and distal parts of ExtTi (Fig. 12). Neither the Tyr1A nor the Oamb receptors were detected in muscle cDNA (Fig. 11C, red in ExtTi column). cDNA for all these receptors were found in the CNS (Fig. 11C, green in brain column).
The transcriptomic analysis of the ExtTi muscle identified transcripts for the $\mathrm{GABA}_{\mathrm{B}}$ receptor (see Table 2). Thus, in addition to its known inhibitory ionotropic effects on the muscle, GABA may also have metabotropic effects on it. Investigating this issue would be difficult because, at least in lobster, GABA causes presynaptic inhibition via a G-protein-mediated mechanism (Miwa et al., 1990), presynaptic inhibition is present in at least sensory-motor pathways in stick insect (Sauer et al., 1997), and many vertebrate GABA receptor agonists and antagonists do not work well in arthropods (Jackel et al., 1994; Pearstein et al., 1996). Moreover, our primary focus in this work was on investigating stick insect leg peptidergic modulation prompted by the availability of the neuropeptide inventory in Liessem et al. (2018). We therefore did not further investigate this issue.

Importantly, no transcripts for any receptor except MIP's were found in ExtTi for any of the peptides contained in T1-T3 ganglia neurons with axons in ganglia nerves. Thus, the peptides contained in these axons cannot act on ExtTi in a local hormone like fashion, since the muscle does not contain the receptors to respond to such release.

ExtTi did have receptors for insulin-like peptide and proctolin (Table 3). Since these peptides were not in neurons innervating the muscle, they may be hemolymph-borne modulators in stick insect.

In summary, the excitatory leg motor neurons contain no peptide co-transmitters. MIP is present in the dedicated pathways known to regulate muscle activity, the CI and DUM neuron groups. All CI and DUM neurons contain MIP, and none contain any other peptide modulator. Of the peptides contained in T1-T3 ganglia neurons with axons in ganglia nerves, the muscle has only MIPRs. Modulation in this system thus appears much simpler than that in other described preparations.

\section{MIP decreases ExtTi slow fiber contraction and thus} increases whole-muscle contraction and relaxation dynamics We tested for MIP effects on ExtTi muscle contraction induced both by fCO mechanical stimulation and $n l 3$ electrical stimulation. fCO stimulation elicits a resistance reflex. Our fCO apodeme elongation amplitude and frequency elicited SETi firing and a small amount of unavoidable $\mathrm{CI}_{1}$ firing, but no FETi firing after the first few cycles (Bässler, 1983, 1993; Bässler and Stein, 1996). Our $n l 3$ stimulations, alternatively, elicited action potentials in $\mathrm{SETi}, \mathrm{FETi}$, and $\mathrm{CI}_{1}$ simultaneously and reliably throughout the experiment.

\section{$M I P$ reduced ExtTi contractions induced by fCO stimulation}

Isometric force production and isotonic muscle shortening were examined in separate experiments. SETi and $\mathrm{CI}_{1}$ activity was monitored by $n l 3$ and $n l 2$ or $n l 5$ extracellular recordings. SETi activity and evoked muscle response was highest during apodeme elongation, which mimics FT joint flexion (Bässler, 1983). Figure 13 shows data for one isometric and one isotonic experiment. For both $n=5$ and all statistical tests were unpaired Student's $t$ tests. MIP application reduced both isometric contraction force (force reduced from $12.8 \pm 1.8$ to $4.9 \pm 0.8 \mathrm{mN}$, $p<0.0001$; Fig. 13A) and isotonic contraction shortening (shortening reduced from $316 \pm 12$ to $205 \pm 36 \mu \mathrm{m}, p=0.0002$; Fig. $13 B$ ). No differences in SETi (isometric: $82.9 \pm 2.6 \mathrm{~Hz}$ saline, $81.8 \pm 6 \mathrm{~Hz}$ MIP, $p=0.7216$; isotonic: $36.8 \pm 1.9 \mathrm{~Hz}$ saline, $37.2 \pm 3.1 \mathrm{~Hz} \mathrm{MIP}, p=0.7937$ ) or $\mathrm{CI}_{1}$ (isometric: $2.7 \pm 6.7 \mathrm{~Hz}$ saline, $1.1 \pm 7.4 \mathrm{~Hz}$ MIP, $p=0.2615$; isotonic: $25.5 \pm 23.8 \mathrm{~Hz}$ saline, $20.2 \pm 26.1 \mathrm{~Hz}$ MIP, $p=0.7468$ ) firing were observed in the saline and MIP conditions. The reductions in contraction force 


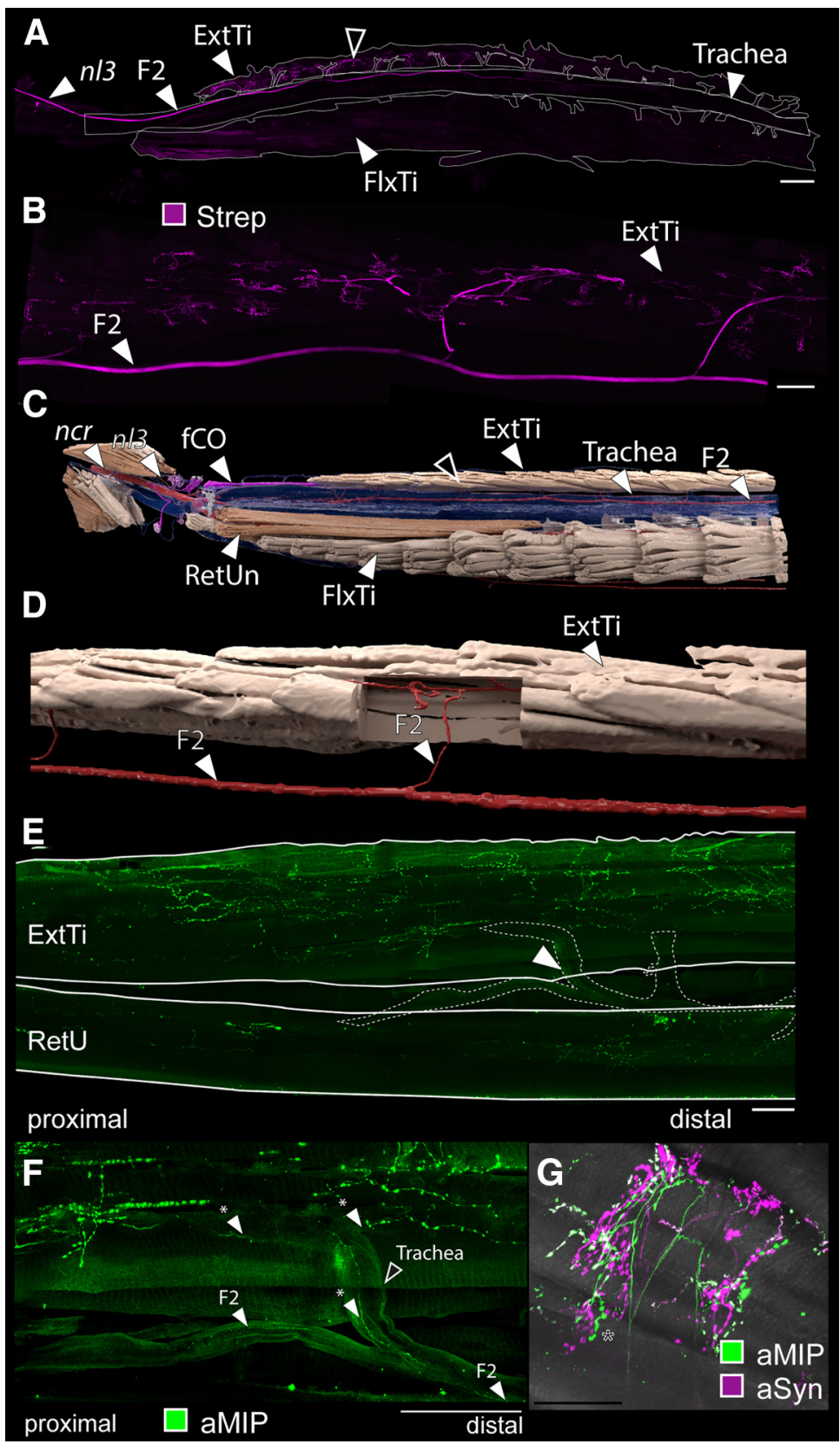

Figure 9. Neuromuscular innervation of ExtTi muscles via nerve F2. $\boldsymbol{A}$, Anterograde fill of $n / 3$, which fuses with $n c r$, from which nerve F2 leaves more distally to innervate ExtTi (Fig. 1). The neuronal tracer (magenta) revealed the F2 projection pattern and structure of nerve terminals on ExtTi. Because the long diffusion distance, visualizing the innervation of the most distal part of the muscle was not possible without risking tissue degradation. Scale bar: $500 \mu \mathrm{m}$. $\boldsymbol{B}$, Magnification of region in $\boldsymbol{A}$ (black arrowhead) showing F2 running parallel to the main trachea and branching off to the muscle when the main trachea does. F2 then splits and runs along the muscle proximally and distally in a modular fashion, with only minor overlap between neighboring F2 innervations. Scale bar: $100 \mu \mathrm{m}$. C, SR- $\mu$ CT visualization of middle leg inner anatomy (beige, muscles; red, nerves; magenta, sensory structures; blue, diaphragm and trachea). $\boldsymbol{D}$, Magnification of region in $\boldsymbol{C}$ (black arrowhead) showing $\mathrm{F} 2$ innervation of ExtTi. A very similar innervation as that in $\boldsymbol{A}, \boldsymbol{B}$ is apparent. $\boldsymbol{E}$, MIP immunoreactivity (green) on ExtTi and RetUn muscle fibers. White arrowhead marks region where a single F2 axon ran along the trachea to the muscle. It then split into proximal and distal regions (similar to $\boldsymbol{B}, \boldsymbol{D}$ ). White dotted outline shows trachea. Scale bar: $50 \mu \mathrm{m}$. $\boldsymbol{F}$, Magnification of region in $\boldsymbol{E}$ (white arrowhead) showing at least one axon immunoreactive to MIP in F2. The projection pattern of this axon (white arrowheads with asterisks) is very similar to that in $\boldsymbol{B}, \boldsymbol{D}$, suggesting that this is the F2 nerve innervating ExtTi. Immunoreactive varicosity-like structures with sizes ranging from 2 to $3 \mu \mathrm{m}$ are visible along the muscle. Scale bar: $75 \mu \mathrm{m}$. G, Double labeling against Synapsin (magenta) and MIP (green) with an underlying brightfield image of the muscle fibers. The image shows several MIP immunoreactive beaded structures (green, 1-3 $\mathrm{m}$ in size), larger presynaptic sites labeled with aSynapsin (magenta, 1.5-8 $\mu \mathrm{m}$, the larger presumably NMJs), and co-labeled synaptic boutons (white, 2-3.5 $\mu \mathrm{m}$ ). Scale bar: $50 \mu \mathrm{m}$. and shortening were therefore not because of changes in SETi and $\mathrm{CI}_{1}$ activity.

MIP effects on muscle contractions induced by FETi, SETi, and $\mathrm{CI}_{1}$ electrical excitation

Figure $14 \mathrm{~A}$ shows isometric contraction muscle force induced by $n l 3$ electrical stimulation in saline and MIP in a representative experiment. In saline, mean isometric force was $76.9 \pm 0.2 \mathrm{mN}$. MIP application reduced force over the course of several stimulation trials until it reached a constant level of $50.7 \pm$ $2.6 \mathrm{mN}$. During wash, force slowly recovered to $68.7 \pm 0.9 \mathrm{mN}$. Unlike the fCO stimulation experiments, MIP never had any effect on muscle shortening in isotonic contractions in the nerve stimulation experiments (Fig. 14B; for proposed explanation of this difference, see Discussion). Figure $14 B$ also shows that FG application alone did not alter isotonic muscle contraction.

Across-experiment grouped data of MIP and $F G$ effects on fCO-induced muscle

contractions

In the fCO work, contractions with similar SETi and $\mathrm{CI}_{1}$ activities in saline and MIP were compared. These contractions were always the contraction immediately before, and the second contraction after, MIP application. Across-experiment data (all comparisons in this and next paragraph paired Student's $t$ tests, $n=8$ ) showed that SETi (isometric: $57.8 \pm 23.1 \mathrm{~Hz}$ saline, $53.5 \pm 19.4 \mathrm{~Hz}$ MIP, $p=0.0856$; isotonic: $27.8 \pm 11.8 \mathrm{~Hz}$ saline, $23.9 \pm 11.2 \mathrm{~Hz} \mathrm{MIP}, p=0.0791)$ and $\mathrm{CI}_{1}$ (isometric: $18.1 \pm 14.1 \mathrm{~Hz}$ saline, $18.8 \pm 14.6$ $\mathrm{Hz}$ MIP, $p=0.8614$; isotonic: $25.6 \pm 14.4 \mathrm{~Hz}$ saline, $27.9 \pm 12.2 \mathrm{~Hz}$ MIP, $p=0.2125)$ mean activities did not differ in saline and MIP.

In isometric contractions, MIP application substantially (Fig. 15A) reduced force production $(27.6 \pm 15.6 \mathrm{mN}$ in saline; $16 \pm 12.6 \mathrm{mN}$ in MIP, $p=0.0002)$. MIP application also substantially reduced shortening amplitude $(228 \pm$ $136 \mu \mathrm{m}$ in saline; $126 \pm 120 \mu \mathrm{m}$ in MIP, $p=$ 0.0009) under isotonic conditions (Fig. 15B). When normalized to their respective control group, MIP reduced mean force to $54 \pm 14 \%$ and mean shortening amplitude to $48 \pm 23 \%$. The fCO experiments were more difficult to continue for long periods of time, and we could therefore not always attempt a wash in them. In the eight experiments in which a wash was attempted, responses were partially restored in five (data not shown; but Fig. 14A shows an example with $n l 3$ electrical stimulation).

Across-experiment grouped data of MIP effects on nl3 stimulation-induced contractions

In these experiments all FETi, SETi, and $\mathrm{CI}_{1}$ axons were electrically stimulated. Therefore, after MIP's effects had stabilized, all 
Table 2. Predicted neurotransmitter receptor protein-coding sequences of C. morosus obtained from a previously published transcriptome of the CNS (SRR4423265) and/or transcripts of the leg muscle preparation (muscle, SRR9134259)

\begin{tabular}{|c|c|c|c|c|c|}
\hline Designation & CNS & Muscle & Complete & GPCR & Accession \\
\hline 5-Hydroxytryptamine receptor & $X$ & & $X$ & $X$ & MT879296 \\
\hline Metabotropic GABA-B receptor subtype 1 & $X$ & $X$ & $X$ & $X$ & MT879297 \\
\hline Sodium-dependent and chloride-dependent GABA transporter ine & $X$ & $X$ & $X$ & & MT879298 \\
\hline Sodium-dependent and chloride-dependent GABA transporter 1 & $X$ & & $X$ & & МT879299 \\
\hline Sodium-dependent and chloride-dependent GABA transporter 2 & $X$ & & $X$ & & MT879300 \\
\hline GABA receptor subunit $\beta$ & $X$ & & $X$ & & MT879301 \\
\hline GABA receptor subunit $\alpha$-6-like isoform X1 & & $X$ & $X$ & & MT879302 \\
\hline GABA receptor subunit $\alpha$-6-like isoform X2 & $X$ & $X$ & $X$ & & MT879303 \\
\hline Metabotropic glutamate 1-like receptor isoform X1 & $x$ & & $X$ & $X$ & MT879305 \\
\hline Metabotropic glutamate 1-like receptor isoform X2 & $X$ & & $X$ & $X$ & MT879304 \\
\hline Metabotropic glutamate 2-like receptor & $X$ & & $X$ & $X$ & MT879306 \\
\hline Metabotropic glutamate 3-like receptor & $x$ & & & & MT879307 \\
\hline Kainate-selective glutamate receptor 1 & $X$ & & $X$ & & MT879308 \\
\hline Ionotropic glutamate receptor kainate 2-like isoform X1 & $X$ & $X$ & & & MT879309 \\
\hline Ionotropic glutamate receptor kainate 2-like isoform X2 & $X$ & & & & MT879310 \\
\hline Ionotropic glutamate receptor kainate 2-like isoform X3 & & $X$ & $X$ & & MT879311 \\
\hline Ionotropic glutamate receptor kainate 2-like isoform X4 & $X$ & & $X$ & & MT879312 \\
\hline Ionotropic glutamate receptor kainate 2-like isoform X5 & & $X$ & $X$ & & MT879313 \\
\hline Ionotropic glutamate receptor kainate 2-like isoform X6 & & $X$ & & & MT879314 \\
\hline Nicotinic $\mathrm{ACH}-\beta 1$ receptor & $x$ & & $X$ & & MT879315 \\
\hline Nicotinic $\mathrm{ACH}-\beta 2$ receptor & $X$ & & $X$ & & MT879316 \\
\hline Nicotinic ACH- $\alpha 1$ receptor & $X$ & & & & MT879317 \\
\hline Nicotinic $\mathrm{ACH}-\alpha 2$ receptor & $X$ & & $X$ & & MT879318 \\
\hline Nicotinic ACH- $\alpha 6$ receptor & $X$ & $X$ & $X$ & & MT879319 \\
\hline Nicotinic $\mathrm{ACH}-\alpha 7$ receptor & $X$ & & & & MT879320 \\
\hline Nicotinic $\mathrm{ACH}-\alpha 8$ receptor isoform $\mathrm{X} 1$ & $x$ & & $X$ & & MT879321 \\
\hline Nicotinic $\mathrm{ACH}-\alpha 8$ receptor isoform $\mathrm{X} 2$ & $x$ & & $X$ & & MT879322 \\
\hline 0ctopamine receptor $0 \mathrm{amb}$ & $x$ & & & & MT879323 \\
\hline 0ctopamine receptor $0 \mathrm{ct} \beta 2 \mathrm{R}$ & $X$ & & $X$ & $X$ & MT879324 \\
\hline Tyramine receptor Tyr1A & $X$ & & $X$ & $X$ & MT879325 \\
\hline Tyramine receptor Tyr2A & $x$ & & & & MT879326 \\
\hline$\alpha 2$-adrenergic-like octopamine receptor & $x$ & & & & MT879327, MT879328, MT879329 \\
\hline
\end{tabular}

CNS and muscle indicate if these transcripts were found in the CNS or muscle transcriptome, respectively. Sequences marked "-" were obtained from other, not yet uploaded transcriptome datasets. Near complete receptor sequences were analyzed for GPCR motifs.

MIP contractions in each experiment could be compared with an equal number of saline contractions. In all experiments MIP's effects stabilized two or three stimulation cycles after MIP application (Fig. 14A). All comparisons repeated measures one-way ANOVA with $n=6$. MIP application (Fig. 15C) decreased group mean isometric force $17.1 \mathrm{mN} \quad(73.6 \pm 17.3 \mathrm{mN}$ saline, $56.5 \pm 14 \mathrm{mN}$ MIP, $p=0.0070)$. Normalizing muscle responses to their respective control group showed that MIP reduced mean force to $77 \pm 7 \%$. In these experiments, MIP induced the same amount of force reduction as in fCO experiments (Fig. 15A,C). The consistency of the motor neuron stimulation allowed for longer experiment durations. We could therefore perform washes in all experiments. Wash mean force (Fig. 15C) increased $23 \mathrm{mN}$ compared with MIP mean force $(56.5 \pm 14 \mathrm{mN}$ MIP, $79.5 \pm 14.9 \mathrm{mN}$ wash, $p=0.0026)$, with no significant difference between control and wash mean force $(p=0.4276)$.

MIP's effects under isotonic conditions varied across experiments (in one experiment even substantially increasing shortening; Fig. 15D). Consequently, although MIP application decreased group mean contraction amplitude by $15 \mu \mathrm{m}(307 \pm 111 \mu \mathrm{m}$ saline, $292 \pm 116 \mu \mathrm{m}$ MIP), saline and MIP grouped means did not differ $(p>0.9999, n=9)$.

\section{FG comparisons}

Data from three experiments in which FG was applied alone under isotonic conditions with $\mathrm{fCO}$ or $n l 3$ stimulation $(n=3$ each) showed that FG did not affect muscle contractions [fCO stimulation: mean decrease $1 \mu \mathrm{m}$ in FG $(98 \pm 8 \mu \mathrm{m}$ saline, $97 \pm 16 \mathrm{FG}, p=0.9418)$, isotonic electrical stimulation: decrease of $0 \mu \mathrm{m}(310 \pm 56 \mu \mathrm{m}$ saline, $310 \pm 57 \mu \mathrm{m} \mathrm{FG}, p=0.9701)$, both paired Student's $t$ test; data not shown].

MIP does not alter muscle passive force production

In small limbs, static and transient passive muscle forces can play important roles in generating movement (Hooper et al., 2009; Wu et al., 2012; von Twickel et al., 2019). We therefore tested whether MIP affected ExtTi passive forces. Visual examination of the data showed that MIP had no effect ( $n=5$; data not shown).

\section{Discussion}

Most well-studied examples of modulation are complex, with large numbers of modulators and modulator co-release with the transmitters that drive the follower's "primary" response (e.g., excitation). Modulation of the stick insect leg, alternatively, is remarkably simple. Leg muscle excitatory motor neurons serve no modulatory role, acting only to generate muscle contraction. The CI and DUM neurons serve only as regulators, CI through GABA ionotropic inhibition and MIP and possibly GABA metabotropic effects, and DUM through octopaminergic and MIP metabotropic effects. Follower driving and modulatory state are thus completely uncoupled. CI and DUM input can set muscle "state" at any level independent of excitatory motor neuron activity. Excitatory motor neurons can drive the muscles at 
Table 3. Predicted neuropeptide receptor protein-coding sequences of C. morosus obtained from a previously published transcriptome of the CNS (SRR4423265) and/or transcripts of the leg muscle preparation (muscle, SRR9134259)

\begin{tabular}{|c|c|c|c|c|c|}
\hline Designation & CNS & Muscle & Complete & GPCR & Accession \\
\hline Adipokinetic hormone receptor isoform X1 & $X$ & & $x$ & $x$ & МT879330, МT879331 \\
\hline Adipokinetic hormone receptor isoform X2 & $X$ & & $x$ & $x$ & MT879332 \\
\hline Allatostatin-A receptor & $X$ & & $x$ & $x$ & MT879333 \\
\hline Allatostatin-C-like receptor & $x$ & & $x$ & $x$ & МT879336 \\
\hline Allatotropin receptor & $x$ & & $x$ & $x$ & MT879337 \\
\hline CAPA-PVK receptor (Cap2b) & $X$ & & & & MT879338 \\
\hline Calcitonin receptor CT-DH isoform X2 & $x$ & & $x$ & $x$ & MT879341 \\
\hline Calcitonin receptor CT-DH isoform X3 & & $x$ & & & MT879342 \\
\hline CCHamide-1 receptor & $x$ & & $x$ & $x$ & MT879343 \\
\hline CCHamide-2 receptor & $x$ & $x$ & $x$ & $x$ & MT879344 \\
\hline Diuretic hormone receptor CRF-DH isoform X1 & $x$ & & $x$ & $x$ & MT879345 \\
\hline Diuretic hormone receptor CRF-DH isoform X2 & $x$ & & $x$ & $x$ & МT879346 \\
\hline Myosuppressin receptor & $x$ & & $x$ & $x$ & MT879355 \\
\hline MIP/sex peptide receptor & $x$ & $x$ & & $x$ & MT879357, MT879358, MT879356, this paper \\
\hline Pigment dispersing factor receptor isoform X1 & $x$ & & $x$ & $x$ & MT879359 \\
\hline Pigment dispersing factor receptor isoform $\mathrm{X} 2$ & $x$ & & $x$ & $x$ & MT879360 \\
\hline Proctolin receptor & $x$ & $x$ & & & МТ879361, МТ879362 \\
\hline sNPF receptor & $x$ & $x$ & & & MT879363 \\
\hline Tachykinin-like peptides receptor isoform X1 & $x$ & $x$ & $x$ & $x$ & MT879364, MT879365 \\
\hline Tachykinin-like peptides receptor isoform X2 & $x$ & $x$ & $x$ & $x$ & МT879366 \\
\hline Trissin receptor & $x$ & & & & MT879367 \\
\hline
\end{tabular}

CNS and muscle indicate if these transcripts were found in the CNS or muscle transcriptome, respectively. Sequences marked with "_" were obtained from other, not yet uploaded transcriptome datasets. Near complete receptor sequences were analyzed for GPCR motifs.

\begin{tabular}{|c|c|c|c|c|}
\hline 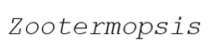 & \multicolumn{4}{|c|}{ IANTLIVVVI } \\
\hline Carausius & \multicolumn{4}{|c|}{-----------"TAVNYLNVTCELP IRYAQPMYGY IVPF LLVVTI IANTL IVVVLSKRHMRTPTNAVLMAMA } \\
\hline & \multicolumn{4}{|c|}{ 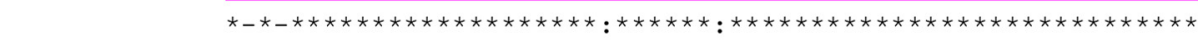 } \\
\hline Zootermopsis & \multicolumn{4}{|c|}{ LSDMFTLLFPAPWLFYMYTFGNHYKPLSPVGACYAWNIMNEVIPAMFHTAS IWLTLALAVQRY IYVCHAPMAR } \\
\hline$s$ & \multicolumn{4}{|c|}{ LCDMFTLLFPAPWLFYMYTFGNHPRPLSPI GACYVWS IMHEVIPATFHTAS IWLTMALAVQRY IYVCHAPVAR } \\
\hline & \multicolumn{4}{|c|}{ 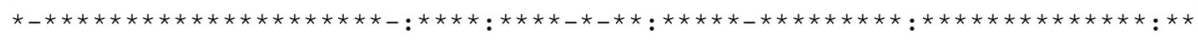 } \\
\hline Zootermopsis & \multicolumn{4}{|c|}{ TWCTMPRVLKCVGIIALLATLHQSTRFVDRVYKPLEVRWE-DDKVVTVCQH IWANWV-TY INLDVYFTFYFCE } \\
\hline us & \multicolumn{4}{|c|}{ TWCTMPRVLRGVAAIGVLAALHQSTRFFDREYVPLDIEWPVGTGNATVCHVQNARWVEQWVGVDLYFTFFFSF } \\
\hline & \multicolumn{4}{|c|}{ 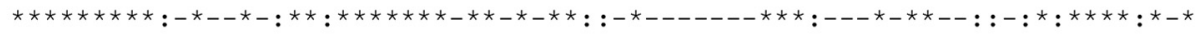 } \\
\hline Zoot & \multicolumn{4}{|c|}{ RVIFVHVVPCVSLVVLNVLLFRAMREAQLKREKLFKENRKNECKRLWDSNCTTLMLIVVVTVFLLVEIPLAVV } \\
\hline Car & \multicolumn{4}{|c|}{$\overline{\text { RVVFVHTVPCVSLVVLNVLLFRAMRDAQLRREKLLKENRSSESKKLRDANCTTLMLIVVVSVFLLVEIPLAVV }}$} \\
\hline & \multicolumn{4}{|c|}{ 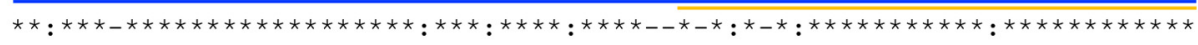 } \\
\hline Zootermol & \multicolumn{4}{|c|}{ TVLHI ISSSVTEILDYS IANVLI LFTNFFI IVSYPINFAIYCGMSRQFRETFKELFVRGTVTTRANGGSSRYS } \\
\hline Carc & \multicolumn{4}{|c|}{$\overline{\text { TMLHI ISSSVVEI LDYSVANVLVLFTNFFI IVSYPINFAIYCGMSRQFRETFKELFVRGAVVARRNGGSSRYS }}$} \\
\hline & \multicolumn{4}{|c|}{ 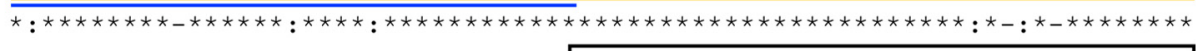 } \\
\hline Zootermopsis & \multirow{2}{*}{$\frac{\text { LVNGPRTCTNETVL }}{\text { LVNGPRTCTNETVL }}$} & \multirow[t]{2}{*}{ CNS 1} & Muscle & MIPR_A \\
\hline Cara & & & & MIPR_B \\
\hline
\end{tabular}

Figure 10. Sequence alignment of the sex peptide/MIPR from Z. nevadensis (accession: XP_021921718.1) and predicted orthologous receptor fragments from C. morosus. C. morosus sequence predicted from three transcriptome entries (CNS 1, Muscles 1 and 2; colored underlines) and two CDNAs (MIPR_A and MIPR_B, colored overlines) as follows: CNS 1 is from a previously published assembly of the CNS (SRR4423265), Muscles 1 and 2 from a leg muscle assembly (SRR9134259). MIPR_A and MIPR_B are RT-PCR products from brain and muscle, respectively. In regions of overlap the sequences were identical, supporting the accuracy of our prediction. Predicted sequence is nearly complete and $81 \%$ identical to $Z$. nevadensis sequence; $*$ identical amino acid; : similar amino acid; - different amino acid.

any frequency and for any duration at each modulatory level. The functional advantages of this separation are so obvious that the most apt question is not "Why is stick insect modulation so simple?" but rather "Why is modulation in other systems so complex?" The answer may be that regulatory systems are generally not as complex as the relatively few wellunderstood systems to date suggest. At the least, our data indicate that regulation lies on a continuum from simple to complex. 

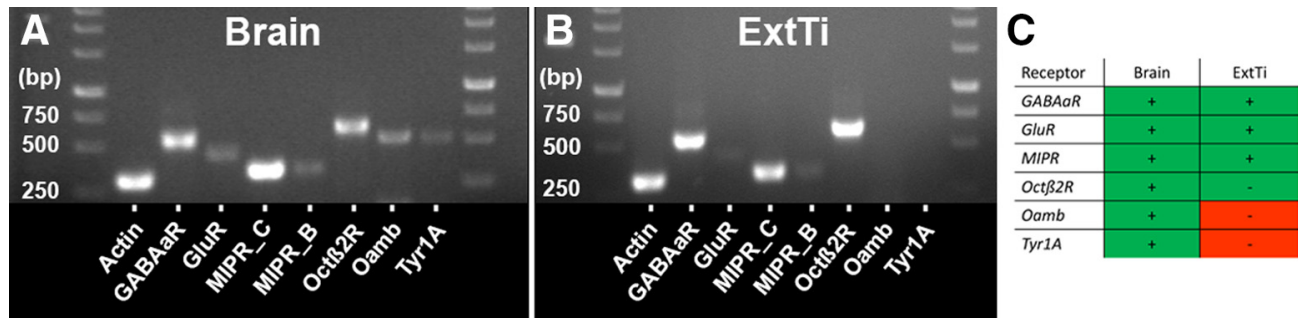

Figure 11. RT-PCR analysis of G-protein-coupled and ionotropic receptors in brain $(\boldsymbol{A})$ and ExtTi $(\boldsymbol{B})$ showed MIPR expression in both (primer sets for MIPR_B and MIPR_C; see Table 1). All tested receptors were expressed in brain, but the 0amb and Tyr $1 A$ receptors were not in the muscle. We tested for actin expression in both tissues as a control. $C$, Summary of RT-PCR data in $\boldsymbol{A}, \boldsymbol{B}$ and transcriptome results. Transcriptome analysis showed that all tested receptors were present in brain (plus signs), but $0 \mathrm{ct} \beta 2 \mathrm{R}$ and the 0amb and Tyr $1 \mathrm{~A}$ receptors were absent in ExtTi (minus signs in bottom three rectangles, ExtTi column). RT-PCR found all tested receptors in brain (green, brain column), but not the Oamb and Tyr1A receptors in ExtTi (red, ExtTi column). The transcriptome and RT-PCR analysis thus agreed for all but the $0 \mathrm{ct} \beta 2 \mathrm{R}$ gene. $0 \mathrm{ct} \beta 2 \mathrm{R}$ 's absence in the muscle transcriptome data could be because of this method being less sensitive than RT-PCR

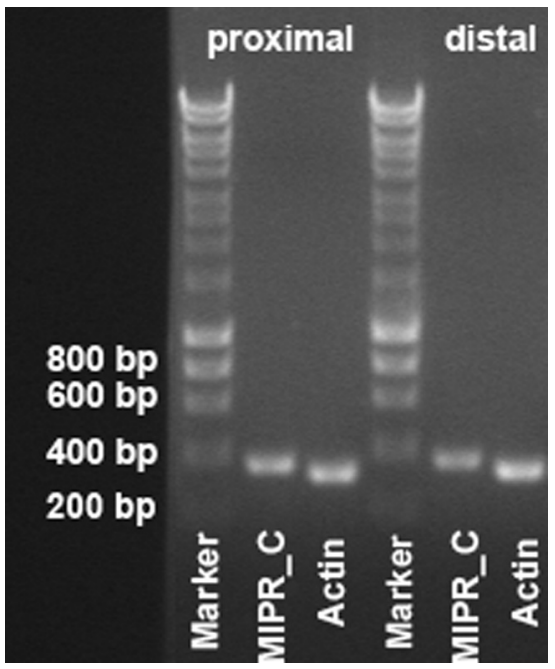

Figure 12. MIPR is expressed in both the most proximal and distal parts of ExtTi (primer for MIPR_C is used here; see Table 1). Primers against actin used as a control.

\section{Experimental limitations}

Given the neuropeptide inventory of Liessem et al. (2018), the high sensitivity of mass spectroscopy and RT-PCR, and their ability to find non-MIP peptides and receptors in non-ExtTi tissues, we have good confidence that, for instance, FMRFamides do not modulate ExtTi. A greater concern is the possible existence of neuropeptides or receptors that do not meet presently understood properties of these molecules, for instance, neuropeptides outside the mass ranges we examined, or receptors lacking the motifs shared by presently known receptors that we used to identify $C$. morosus receptors. With these caveats in mind, our data should therefore be interpreted as showing, using best possible present techniques and understanding of neuromodulatory molecules, that MIP is the only neurally-mediated leg muscle peptide modulator, and is in only CI and DUM neurons.

\section{MIP localization and MIP-receptor expression}

To our knowledge, our data are the first unambiguous demonstration of a neuropeptide in insect CI neurons, and any demonstration in DUM neurons. MIP expression was generally higher in DUM neurons. In vertebrate sympathetic neurons, peptide concentration varies depending on the physiological state of, or input to, the neuron (Kessler et al., 1981; Sun et al., 1992; HyattSachs et al., 1993). Stick insect hemolymph (i.e., hormonal) FMRFamide levels vary in a circadian fashion (Miksys et al.,
1997). These hormonal variations in FMRFamide or AKH alter DUM neuron excitability in cockroach (Wicher, 2001; Predel et al., 2004), which could alter DUM MIP concentration. The differences in MIP concentration in CI and DUM neurons in our data may therefore reflect cell-type-specific differences in overall MIP expression, or circadian differences in the activities of the two neuron types.

Immunohistochemistry of the ExtTi muscle showed a dense network of finely dividing processes with numerous varicositylike structures on the muscle. The size and morphology of these varicosities were similar to peptidergic axon type III terminals (Rao et al., 2001) that would allow for en passant release of neuropeptides along the axon processes (Wong et al., 2012). Neuropeptides are stored in dense-cored vesicles (DCVs). In locust, extensor-innervating DUM neurons have DCVs in their axon terminals (Hoyle et al., 1974) and DCVs have been found in CIs (Titmus, 1981). MIP or other peptidergic modulators may thus be also present in locust DUM and CI.

$\mathrm{SETi}, \mathrm{FETi}$, and $\mathrm{CI}_{1}$ innervation systematically varies along ExtTi length (Bässler et al., 1996). MIPR being expressed in both the most distal and proximal ends of the muscle suggests that DUM innervation, alternatively, is relatively constant along the muscle.

\section{Functional relevance of MIP}

MIP reduced muscle force in both fCO and electrical stimulations. fCO stimulations activated only SETi-innervated (slow) fibers. MIP therefore definitely affected slow fibers. $n l 3$ electrical stimulations also activate FETi-innervated (fast) fibers, and induced contractions $\sim 2.5$ times larger than those induced by fCO stimulation. However, MIP reduced force approximately the same amount (Fig. 15) in both stimulations. The relative decrease was thus much smaller in $n l 3$ stimulation-induced contractions. If MIP affected fast fibers, one might have expected approximately similar relative decreases.

In the isotonic experiments, MIP decreased shortening amplitude in fCO stimulations but not $n l 3$ stimulations. This result also supports the conclusion that MIP primarily affects slow fibers. Fast fibers produce much larger contractions than slow fibers. When both types are equally stimulated, as in $n l 3$ stimulations, fast fiber activity therefore dominates muscle shortening. Under these conditions, the muscle may even shorten more rapidly than the slow fibers can intrinsically shorten. In this extreme, the slow fibers would be slack, contributing nothing to muscle shortening. That MIP did not decrease shortening in these experiments thus again suggests that MIP had no or very little effect on the fast fibers. This situation would not occur in the 
A fCO stim. - isometric
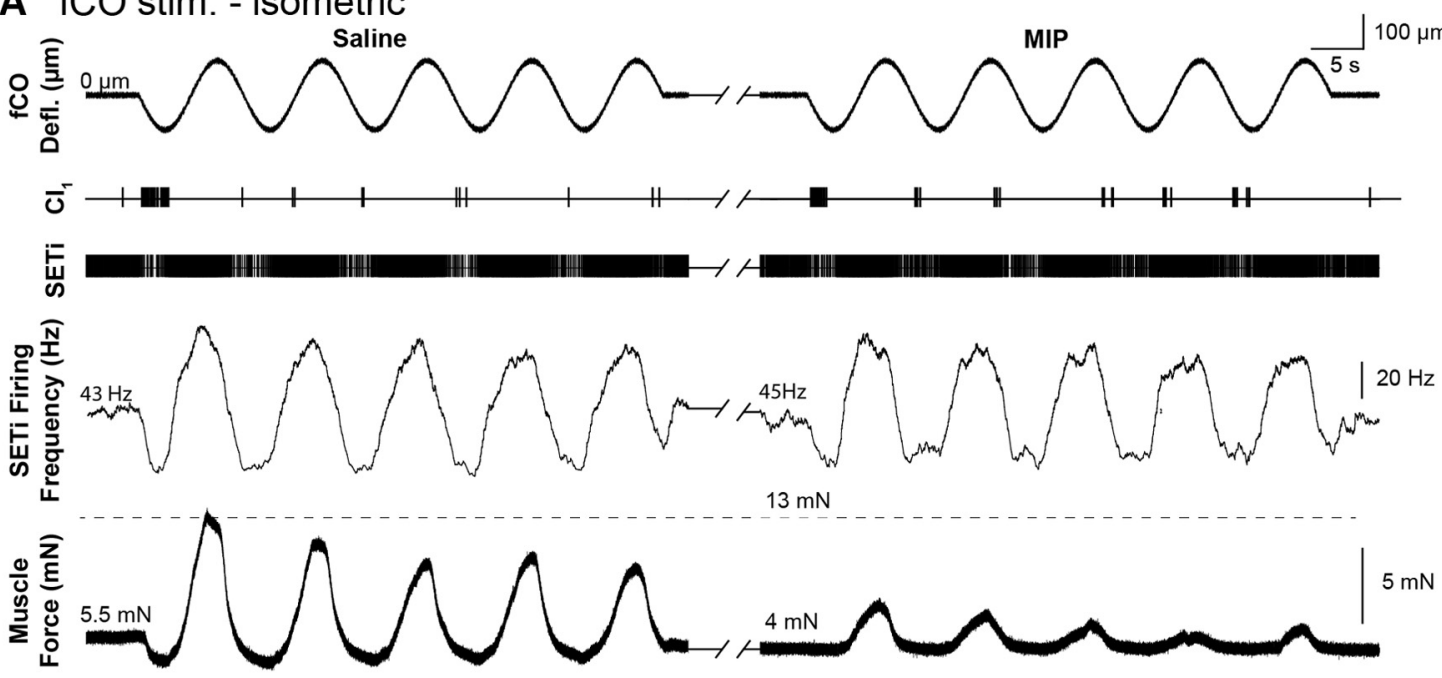

B fCO stim. - isotonic
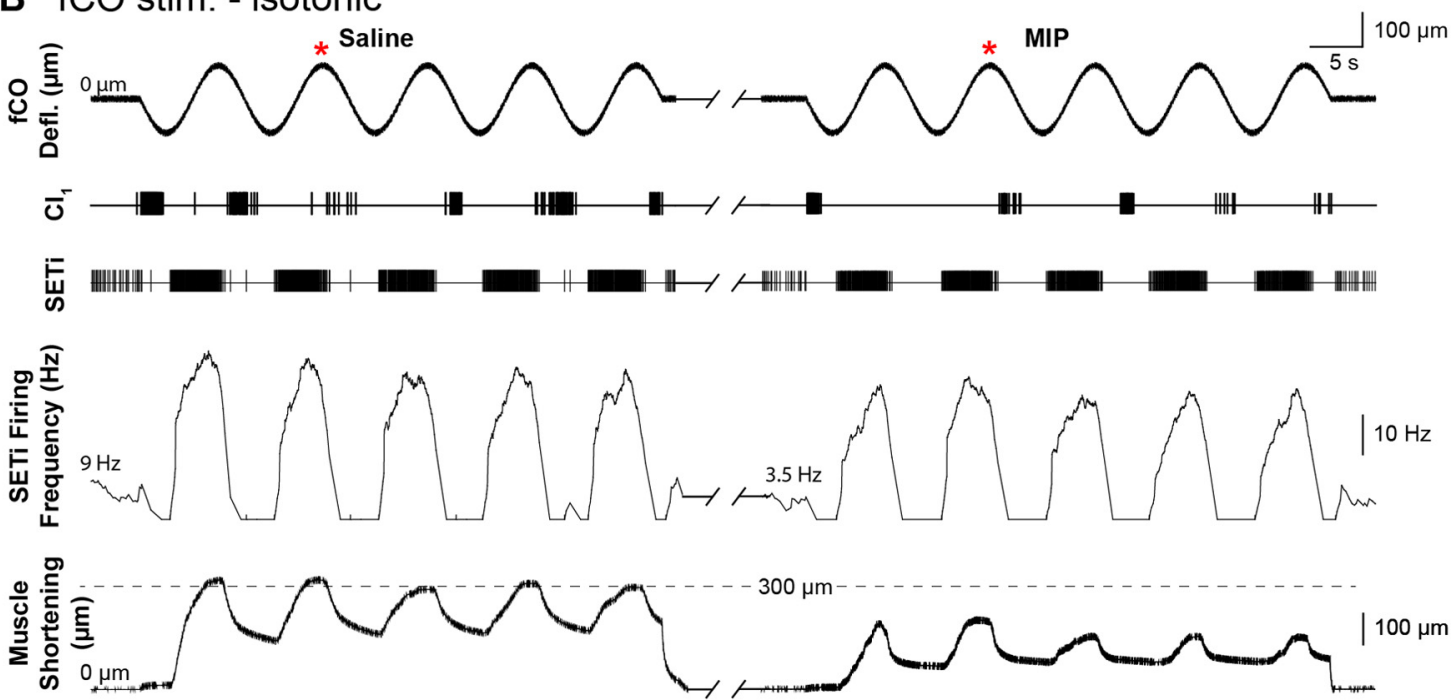

C $\mathrm{Cl}_{1}$ stimulation D SETi and $\mathrm{Cl}_{1}$ activity
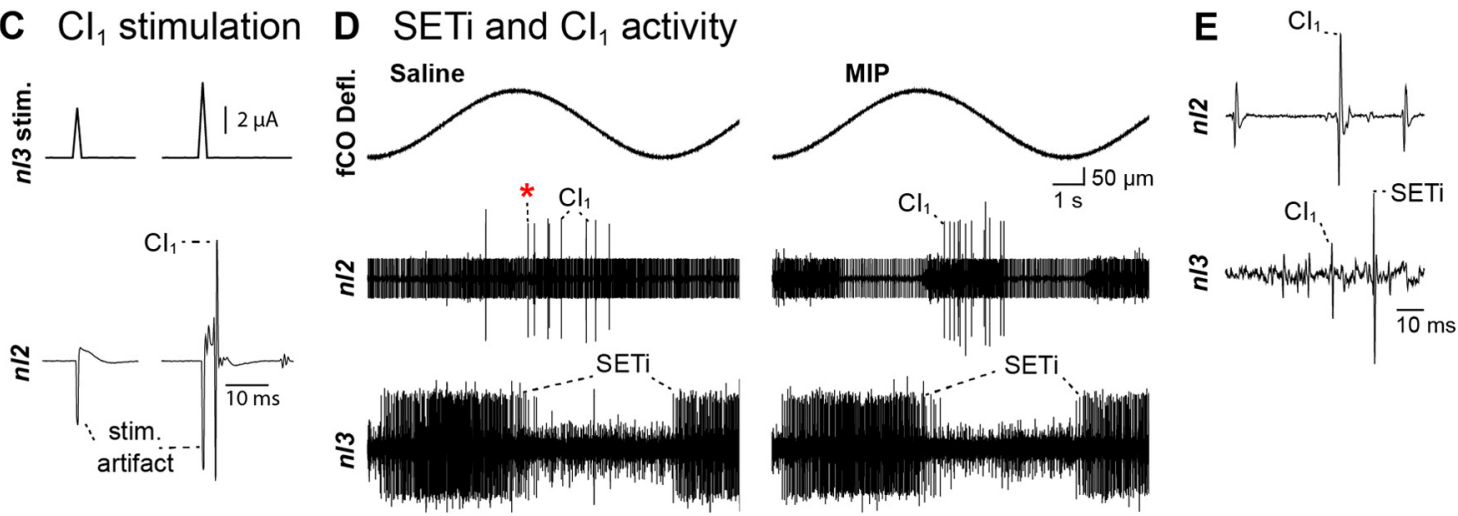

Figure 13. Two representative experiments showing MIP reduction of muscle slow fiber isometric force $(\boldsymbol{A})$ and isotonic shortening $(\boldsymbol{B})$. SETi and $\mathrm{Cl}_{1}$ motor neuron activity induced by sinusoidal deflections of $\mathrm{fCO}$ apodeme. No change in SETi and $\mathrm{Cl}_{1}$ activity was observed. $\mathrm{C}_{\text {, }} \mathrm{Cl}_{1}$ identity confirmed by extracellular recording of $n / 2$ (bottom trace) and stimulation of $n / 3$ (upper trace) with different current amplitudes. Electrical disturbance in $n / 2$ recording coinciding with the stimulus is a stimulus artifact. Higher current amplitude stimulation elicited $\mathrm{Cl}_{1}$ action potentials in $n / 2$. D, Magnification of $n / 2$ and $n / 3$ extracellular recording in $\boldsymbol{B}$ (red asterisks) in saline (left panel) and MIP (right panel). $\mathrm{Cl}_{1}$ and SETi action potentials are labeled. $\boldsymbol{E}$, Magnification of the extracellular nerve recordings marked in $\boldsymbol{D}$ (red asterisk). Cl 1 action potentials are present on $n / 2$ and $n / 3$, SETi activity is present only on $n / 3$.

isometric (force) experiments, in which the muscle is held at a constant length. In these experiments, rather than fast fiber activity negating slow fiber activity, fast and slow force production instead add.
Why have CI activity at all? First, reducing slow fiber activation when it is not needed reduces energy expenditure. Second, during rapidly alternating movements, the slow relaxation of antagonist muscle slow fibers would result in residual slow fiber 
A electric stim. - isometric

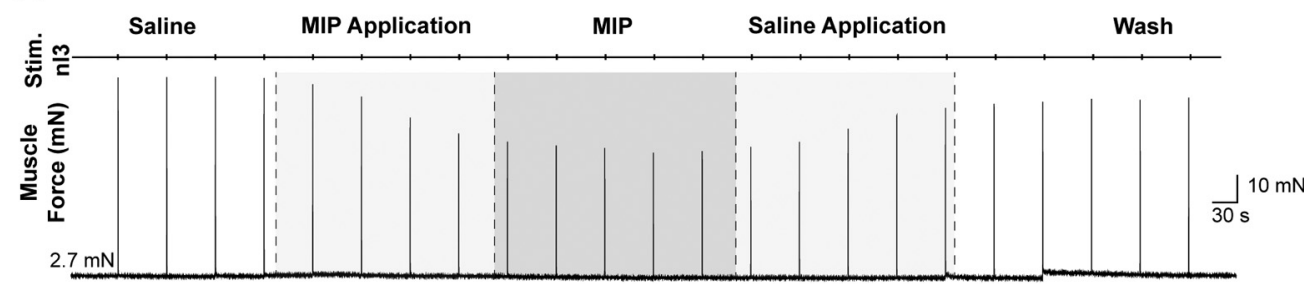

B electric stim. - isotonic

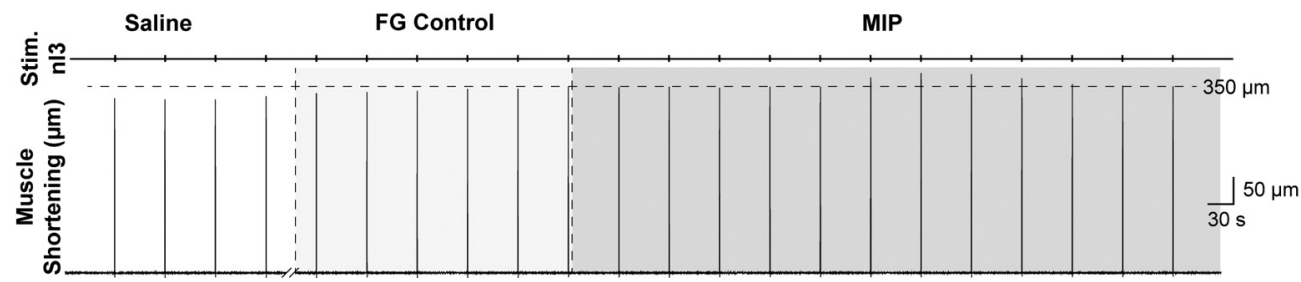

Figure 14. MIP reduced isometric force $(\boldsymbol{A})$ but had no consistent effect on isotonic shortening $(\boldsymbol{B})$ induced by $n / 3$ electrical stimulation. MIP effects on force washed out with perfusion of normal saline. $2.7 \mathrm{mN}$ in muscle force portion of $\boldsymbol{A}$ is muscle passive baseline force.
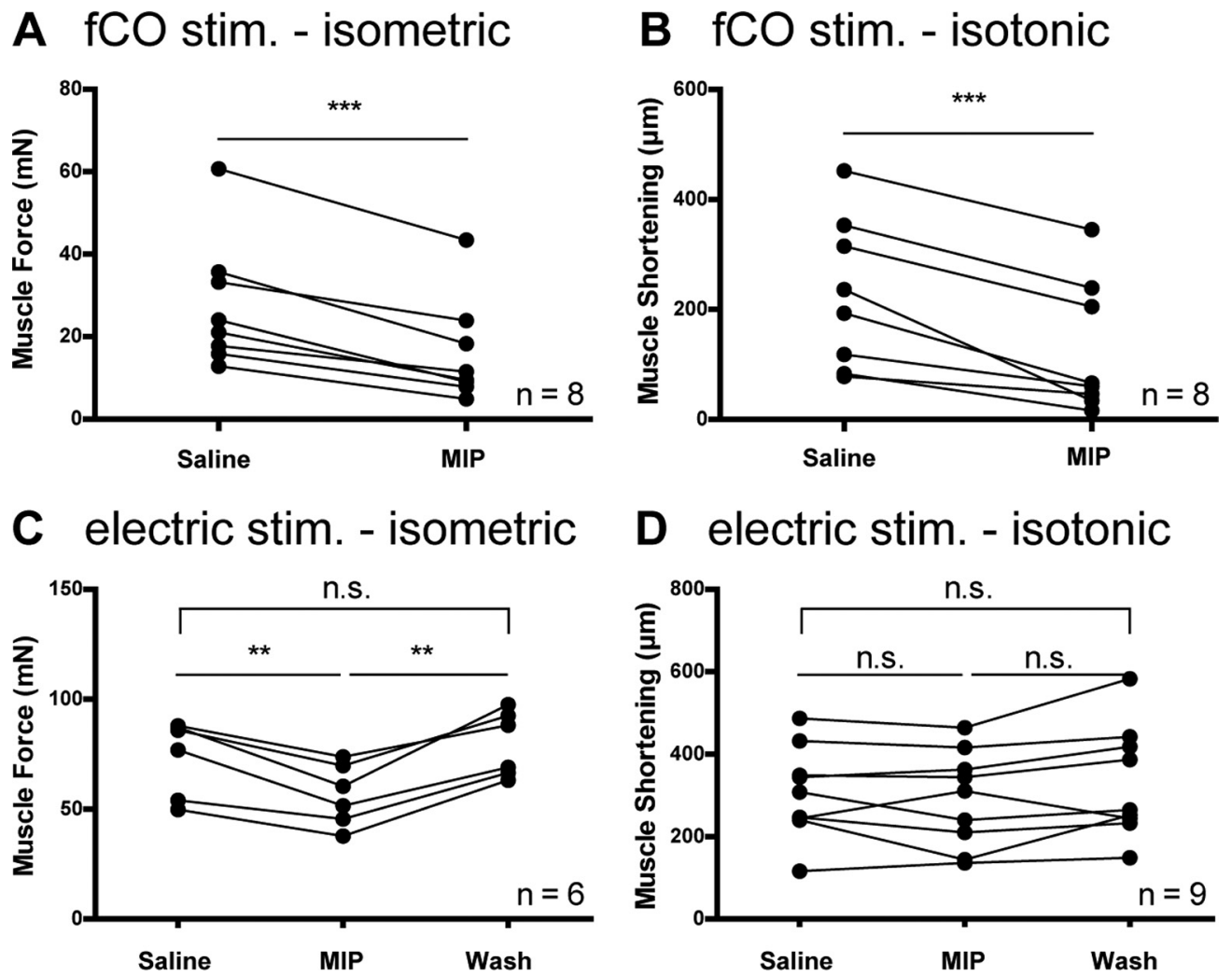

Figure 15. Grouped MIP effects on ExtTi isometric force and isotonic shortening with $\mathrm{fCO}(\mathrm{SETi}$ and $\mathrm{Cl} ; \boldsymbol{A}, \boldsymbol{B})$ and $n / 3$ (SETi, $\mathrm{FETi}$, and $\left.\mathrm{Cl} ; \boldsymbol{C}_{1}, \boldsymbol{D}\right)$ stimulation. $\boldsymbol{A}, \boldsymbol{B}, \mathrm{MIP}$ decreased group means of both isometric force and isotonic shortening [isometric: $11.6 \mathrm{mN}(27.6 \pm 15.6 \mathrm{mN}$ saline, $16 \pm 12.7 \mathrm{mN}$ MIP), $p=0.0002$; isotonic: $102 \mu \mathrm{m}(228 \pm 136 \mu \mathrm{m} \mathrm{saline,} 126 \pm 120 \mu \mathrm{m} \mathrm{MIP})$, $p=0.0009$ ]. C, D, Each data point represents muscle responses averaged over several consecutive stimulation cycles (minimum 3, maximum 6). Isometric force decreased $17.1 \mathrm{mN}$ in MIP $(73.6 \pm 17.3 \mathrm{mN}$ saline, $56.5 \pm 14 \mathrm{mN} \mathrm{MIP,} p=0.007, n=6)$, which was restored on perfusion with normal saline [23 mN increase $(56.5 \pm 14 \mathrm{mN}$ MIP, $79.5 \pm 14.9 \mathrm{mN}$ wash), $p=0.0026]$. Mean force in wash was greater than in saline, but the increase $(5.9 \mathrm{mN} ; p=0.4276)$ was not significant. MIP induced the same force reduction in fCO $(\boldsymbol{A}, 11.6 \pm 4.4 \mathrm{mN})$ and $n / 3(\boldsymbol{C})$ isometric experiments (17.1 $\pm 7.4 \mathrm{mN}$, unpaired Student's $t$ test, $p=0.1041)$. In isotonic conditions at $n / 3$ stimulation, MIP had no significant effect on muscle shortening amplitude. n.S., $p \geq 0.05$; $* 0.01<p<0.05 ; * * 0.001<p \leq 0.01 ; * * * p \leq 0.001$.

force from a preceding movement (e.g., stance) opposing the subsequent movement (swing). SETi and FETi are co-active during fast active leg extension (Schmidt et al., 2001). During rapid movements, reducing SETi induced slow fiber activity would prevent residual slow fiber force from opposing subsequent leg flexion, and thus be advantageous. CI and DUM thus likely work together through their ionotropic $\left(\mathrm{GABA}_{\mathrm{A}}\right)$ and metabotropic (octopamine, MIP, and $\mathrm{GABA}_{\mathrm{B}}$ ) actions to achieve the mixture of slow and fast fiber activation most appropriate for different behaviors, e.g., rest posture versus walking. Leg regulatory 
systems may thus exist, at least in part, to limit slow fiber activity to behaviors in which their slow dynamics are advantageous (Zakotnik et al., 2006). Consistent with this interpretation, and MIP playing an important role in this process, $\mathrm{CI}_{2}$ and $\mathrm{CI}_{3}$, both of which contain MIP (Fig. 7A), innervate the FlxTi muscle (Goldammer et al., 2012).

\section{Colocalization of small-chemical neurotransmitters and neuropeptides}

Co-transmission poses the difficulty of obligatorily coupling release of both transmitters. Both stick insect regulatory pathways (CI, GABA and MIP; DUM, octopamine and MIP) potentially have this problem. Several properties of small-chemical transmitter and neuropeptide release help ameliorate this difficulty. First, peptides and small-chemical transmitters can act on different timescales, be released at different axon terminals, and peptides can diffuse relatively long distances, binding to receptors not accessible to small-chemical transmitters (Nässel, 2009; van den Pol, 2012). Neuropeptides are therefore well suited to modulate relatively distant targets, and large targets such as muscles. Second, the two groups are also differently sensitive to neuron activity, classical transmitter release beginning at low firing frequencies and peptide release generally requiring higher levels of neuron activity (Whim and Lloyd, 1989, 1990; Peng and Horn, 1991; Weiss et al., 1992; Vilim et al., 1996; Karhunen et al., 2001; Whim, 2006).

The DUM and CI neurons could therefore release their small-chemical and neuropeptide transmitters at different release sites, with smaller and larger regions of muscles being affected, and in different quantities, depending on their excitation state. CI-released GABA primarily affects slow ExtTi fibers (Bässler et al., 1996; Bässler and Stein, 1996; Wolf, 2014) and we show here that MIP decreases slow fiber output. The effects of octopamine on stick insect muscle have not been investigated, but in locust it increases muscle relaxation velocity (O'Shea and Evans, 1979; Evans and Siegler, 1982). These data suggest the DUM and CI modulatory pathways work together to increase the animal's ability to create rapid leg movements. Given the results noted above about the differential release of smallchemical and peptide transmitters as a function of releasing-neuron activity, at low levels of activation this increase would primarily occur because of GABA and octopamine release, with MIP playing an increasingly prominent role as DUM and CI activity increased. DUM and CI, and their small-chemical and peptide transmitters, would thus function cooperatively to tune the neuromuscular system to producing rapid locomotory movements.

\section{Functional consequences of individual CI and DUM innervating different muscle groups}

Individual CI and DUM neurons innervate different sets of leg muscles (Mentel et al., 2008; Goldammer et al., 2012). This specificity suggests that, depending on the behavior, different combinations of CI and DUM neurons are activated so that correct sets of muscle are switched to being able to produce fast contractions and relaxations. In such a system, in which functionally-related sets of muscles are the targets, there is no need for muscle-specific modulation such as that observed in Aplysia. In such an organizational structure, there is also no need to evolve different neuromodulators for each muscle group. The large number of CI and DUM modulatory neurons would be sufficient, acting combinatorially, to switch to rapid activity whatever muscle groups any particular behavior required to be so.

\section{References}

Bartos M, Allgäuer C, Eckert M, Honegger HW (1994) The antennal motor system of crickets: proctolin in slow and fast motoneurons as revealed by double labelling. Eur J Neurosci 6:825-836.

Bässler U (1983) Neural basis of elementary behavior in stick insects. Berlin: Springer.

Bässler U (1993) The femur-tibia control-system of stick insects - a model system for the study of the neural basis of joint control. Brain Res Rev 18:207-226.

Bässler U, Storrer J (1980) The neural basis of the femur-tibia-control-system in the stick insect Carausius morosus. Biol Cybernetics 38:107-114.

Bässler U, Stein W (1996) Contributions of structure and innervation pattern of the stick insect extensor tibiae muscle to the filter characteristics of the muscle-joint system. J Exp Biol 199:2185-2198.

Bässler D, Büschges A, Meditz S, Bässler U (1996) Correlation between muscle structure and filter characteristics of the muscle-joint system in three orthopteran insect species. J Exp Biol 199:2169-2183.

Beckmann F, Herzen J, Haibel A, Müller B, Schreyer A (2008) High density resolution in synchrotron-radiation-based attenuation-contrast microtomography. Proc SPIE 70781D:1-13.

Bidaye SS, Bockemühl T, Büschges A (2018) Six-legged walking in insects: how CPGs, peripheral feedback, and descending signals generate coordinated and adaptive motor rhythms. J Neurophysiol 119:459-475.

Bishop CA, Wine JJ, Nagy F, O'Shea M (1987) Physiological consequences of a peptide cotransmitter in a crayfish nerve-muscle preparation. J Neurosci 7:1769-1779.

Blanke A, Machida R, Szucsich NU, Wilde F, Misof B (2015) Mandibles with two joints evolved much earlier in the history of insects: dicondyly is a synapomorphy of bristletails, silverfish and winged insects. Syst Entomol 40:357-364.

Blümel M, Guschlbauer C, Daun-Gruhn S, Hooper SL, Büschges A (2012a) Hill-type muscle model parameters determined from experiments on single muscles show large animal-to-animal variation. Biol Cybern 106:559571.

Blümel M, Hooper SL, Guschlbauer C, White WE, Büschges A (2012b) Determining all parameters necessary to build Hill-type muscle models from experiments on single muscles. Biol Cybern 106:543-558.

Bolger AM, Lohse M, Usadel B (2014) Trimmomatic: a flexible trimmer for Illumina sequence data. Bioinformatics 30:2114-2120.

Camacho C, Coulouris G, Avagyan V, Ma N, Papadopoulos J, Bealer K, Madden TL (2009) BLAST+: architecture and applications. BMC Bioinformatics 10:421.

Chang Z, Li G, Liu J, Zhang Y, Ashby C, Liu D, Cramer C, Huang X (2015) Bridger: a new framework for de novo transcriptome assembly using RNA-seq data. Genome Biol 16:30.

Cropper EC, Lloyd PE, Reed W, Tenenbaum R, Kupfermann I, Weiss KR (1987) Multiple neuropeptides in cholinergic motor neurons of Aplysia evidence for modulation intrinsic to the motor circuit. Proc Natl Acad Sci USA 84:3486-3490.

Davis NT, Dulcis D, Hildebrand JG (2001) Innervation of the heart and aorta of Manduca sexta. J Comp Neurol 440:245-260.

Debrodt B, Bässler U (1989) Motor neurons of the flexor tibiae muscle in phasmids. Zool Jb Physiol 93:481-494.

Dunn TW, Mercier AJ (2005) Synaptic modulation by a Drosophila neuropeptide is motor neuron-specific and requires CaMKII activity. Peptides 26:269-276.

Evans PD, Siegler MV (1982) Octopamine mediated relaxation of maintained and catch tension in locust skeletal muscle. J Physiol 324:93-112.

Field LH, Duch C, Pflüger HJ (2008) Responses of efferent octopaminergic thoracic unpaired median neurons in the locust to visual and mechanosensory signals. J Insect Physiol 54:240-254.

Friedrich H (1933) Nervenphysiologische Studien an Insekten. Z Vergl Physiol 18:536-561.

Gasteiger E, Gattiker A, Hoogland C, Ivanyi I, Appel RD, Bairoch A (2003) ExPASy: the proteomics server for in-depth protein knowledge and analysis. Nucleic Acids Res 31:3784-3788.

Godlewska-Hammel E, Büschges A, Gruhn M (2017) Fiber-type distribution in insect leg muscles parallels similarities and differences in the functional 
role of insect walking legs. J Comp Physiol A Neuroethol Sens Neural Behav Physiol 203:773-790.

Goldammer J, Büschges A, Schmidt J (2012) Motoneurons, DUM cells, and sensory neurons in an insect thoracic ganglion: a tracing study in the stick insect Carausius morosus. J Comp Neurol 520:230-257.

Grabherr MG, Haas BJ, Yassour M, Levin JZ, Thompson DA, Amit I, Adiconis X, Fan L, Raychowdhury R, Zeng Q, Chen Z, Mauceli E, Hacohen N, Gnirke A, Rhind N, di Palma F, Birren BW, Nusbaum C, Lindblad-Toh K, Friedman N, et al. (2011) Full-length transcriptome assembly from RNA-Seq data without a reference genome. Nat Biotechnol 29:644-652.

Graham D (1985) Pattern and control of walking in insects. Adv Insect Physiol 18:31-140.

Gruhn M, Rosenbaum P, Bockemühl T, Büschges A (2016) Body side-specific control of motor activity during turning in a walking animal. Elife 5: e13799.

Guschlbauer C, Scharstein H, Büschges A (2007) The extensor tibiae muscle of the stick insect: biomechanical properties of an insect walking leg muscle. J Exp Biol 210:1092-1108.

Haas BJ, Papanicolaou A, Yassour M, Grabherr M, Blood PD, Bowden J, Couger MB, Eccles D, Li B, Lieber M, MacManes MD, Ott M, Orvis J, Pochet N, Strozzi F, Weeks N, Westerman R, William T, Dewey CN, Henschel R, et al. (2013) De novo transcript sequence reconstruction from RNA-seq using the Trinity platform for reference generation and analysis. Nat Protoc 8:1494-1512.

Hauser F, Williamson M, Cazzamali G, Grimmelikhuijzen CJP (2006) Identifying neuropeptide and protein hormone receptors in Drosophila melanogaster by exploiting genomic data. Brief Funct Genomic Proteomic 4:321-330.

Hewes RS, Taghert PH (2001) Neuropeptides and neuropeptide receptors in the Drosophila melanogaster genome. Genome Res 11:1126-1142.

Hooper SL, Marder E (1984) Modulation of a central pattern generator by two neuropeptides, proctolin and FMRFamide. Brain Res 305:186-191.

Hooper SL, Guschlbauer C, von Uckermann G, Büschges A (2007) Slow temporal filtering may largely explain the transformation of stick insect (Carausius morosus) extensor motor neuron activity into muscle movement. J Neurophysiol 98:1718-1732.

Hooper SL, Guschlbauer C, Blümel M, Rosenbaum P, Gruhn M, Akay T, Büschges A (2009) Neural control of unloaded leg posture and of leg swing in stick insect, cockroach, and mouse differs from that in larger animals. J Neurosci 29:4109-4119.

Hoyle G (1978) Distributions of nerve and muscle fibre types in locust jumping muscle. J Exp Biol 73:205-233.

Hoyle G, Dagan D, Moberly B, Colquhoun W (1974) Dorsal unpaired median insect neurons make neurosecretory endings on skeletal-muscle. J Exp Zool 187:159-165.

Hyatt-Sachs H, Schreiber RC, Bennett TA, Zigmond RE (1993) Phenotypic plasticity in adult sympathetic ganglia in vivo: effects of deafferentation and axotomy on the expression of vasoactive intestinal peptide. J Neurosci 13:1642-1653.

Jackel C, Krenz W, Nagy F (1994) Bicuculline/baclofen-insensitive GABA response in crustacean neurones in culture. J Exp Biol 191:167-193.

Karhunen T, Vilim FS, Alexeeva V, Weiss KR, Church PJ (2001) Targeting of peptidergic vesicles in cotransmitting terminals. J Neurosci 21:RC127.

Katz PS, Frost WN (1996) Intrinsic neuromodulation: altering neuronal circuits from within. Trends Neurosci 19:54-61.

Kessler JA, Adler JE, Bohn MC, Black IB (1981) Substance P in principal sympathetic neurons: regulation by impulse activity. Science 214:335336.

Kittmann R (1991) Gain-control in the femur tibia feedback-system of the stick insect. J Exp Biol 157:503-522.

Kittmann R (1997) Neural mechanisms of adaptive gain control in a joint control loop: muscle force and motoneuronal activity. J Exp Biol 200:1383-1402.

Kwok R, Orchard I (2002) Central effects of the peptides, SchistoFLRFamide and proctolin, on locust oviduct contraction. Peptides 23:1925-1932.

Liessem S, Ragionieri L, Neupert S, Büschges A, Predel R (2018) Transcriptomic and neuropeptidomic analysis of the stick insect, Carausius morosus. J Proteome Res 17:2192-2204.

Marder E (2012) Neuromodulation of neuronal circuits: back to the future. Neuron 76:1-11.
Marder E, Hooper SL (1985) Neurotransmitter modulation of the stomatogastric ganglion of decapod crustaceans. In: Model neural networks and behavior (Selverston AI, Moulins M, eds), pp 319-337. New York: Plenum.

Marder E, Hooper SL, Eisen JS (1987) Multiple neurotransmitters provide a mechanism for the production of multiple outputs from a single neuronal circuit. In: Synaptic function (Edelman GM, Gall WE, Cowan MW, eds), pp 305-327. New York: Wiley, Inc.

Marquardt F (1939) Beiträge zur Anatomie der Muskulatur und der peripheren Nerven von Carausius (Dixippus) morosus. Zool Jahrb Abt Anat Ont Tiere 66:63-128.

Mentel T, Weiler V, Büschges A, Pflüger HJ (2008) Activity of neuromodulatory neurones during stepping of a single insect leg. J Insect Physiol 54:51-61.

Merighi A (2002) Costorage and coexistence of neuropeptides in the mammalian CNS. Prog Neurobiol 66:161-190.

Miksys S, Lange AB, Orchard I, Wong V (1997) Localization and neurohemal release of FMRFamide-related peptides in the stick insect Carausius morosus. Peptides 18:27-40.

Miwa A, Ui M, Kawai N (1990) G protein is coupled to presynaptic glutamate and GABA receptors in lobster neuromuscular synapse. J Neurophysiol 63:173-180.

Nässel DR (2009) Neuropeptide signaling near and far: how localized and timed is the action of neuropeptides in brain circuits? Invert Neurosci 9:57-75.

Neupert S, Fusca D, Schachtner J, Kloppenburg P, Predel R (2012) Toward a single-cell-based analysis of neuropeptide expression in Periplaneta americana antennal lobe neurons. J Comp Neurol 520:694-716.

Norris BJ, Calabrese RL (1987) Identification of motor neurons that contain a FMRFamidelike peptide and the effects of FMRFamide on longitudinal muscle in the medicinal leech, Hirudo medicinalis. J Comp Neurol 266:95-111.

Ormerod KG, LePine OK, Bhutta MS, Jung J, Tattersall GJ, Mercier AJ (2016) Characterizing the physiological and behavioral roles of proctolin in Drosophila melanogaster. J Neurophysiol 115:568-580.

O'Shea M, Evans PD (1979) Potentiation of neuromuscular transmission by an octopaminergic neurone in the locust. J Exp Biol 79:169-190.

Pearstein E, Cattaert D, Clarac F (1996) Crayfish sensory terminals and motor neurones exhibit two distinct types of GABA receptors. J Comp Physiol A Neuroethol Sens Neural Behav Physiol 180:71-79.

Pearson KG, Bergman SJ (1969) Common inhibitory motoneurones in insects. J Exp Biol 50:445-471.

Peng YY, Horn JP (1991) Continuous repetitive stimuli are more effective than bursts for evoking LHRH release in bullfrog sympathetic ganglia. J Neurosci 11:85-95.

Petersen T, Brunak S, von Heijne G, Nielsen H (2011) SignalP 4.0: discriminating signal peptides from transmembrane regions. Nat Methods 8:785786.

Predel R, Rapus J, Eckert M (2001) Myoinhibitory neuropeptides in the American cockroach. Peptides 22:199-208.

Predel R, Neupert S, Wicher D, Gundel M, Roth S, Derst C (2004) Unique accumulation of neuropeptides in an insect: FMRFamide-related peptides in the cockroach, Periplaneta americana. Eur J Neurosci 20:1499-1513.

Rao S, Lang C, Levitan ES, Deitcher DL (2001) Visualization of neuropeptide expression, transport, and exocytosis in Drosophila melanogaster. J Neurobiol 49:159-172.

Russo AF (2017) Overview of neuropeptides: awakening the senses? Headache 57:37-46.

Sahbaz BD, Iyison NB (2019) Prediction and expression analysis of G protein-coupled receptors in the laboratory stick insect, Carausius morosus. Turk J Biol 43:77-88.

Sauer AE, Büschges A, Stein W (1997) Role of presynaptic inputs to proprioceptive afferents in tuning sensorimotor pathways of an insect joint control network. J Neurobiol 32:359-376.

Schmidt J, Gramoll S, Calabrese RL (1995) Segment-specific effects of FMRFamide on membrane properties of heart interneurons in the leech. J Neurophysiol 74:1485-1497.

Schmidt J, Fischer H, Büschges A (2001) Pattern generation for walking and searching movements of a stick insect leg. II. Control of motoneuronal activity. J Neurophysiol 85:354-361.

Sohn JW (2015) Network of hypothalamic neurons that control appetite. BMB Rep 48:229-233. 
Stolz T (2018) Descending octopaminergic neurons in the stick insect: their inputs and their output effects on the locomotor system. Thesis/ Dissertation. Germany: University of Cologne.

Stolz T, Diesner M, Neupert S, Hess ME, Delgado-Betancourt E, Pflüger HJ, Schmidt J (2019) Descending octopaminergic neurons modulate sensoryevoked activity of thoracic motor neurons in stick insects. J Neurophysiol 122:2388-2413.

Storrer J (1976) Systemanalytische Untersuchungen am "Kniesehnenreflex" der Stabheuschrecke Carausius morosus Br. (Orthoptera). Thesis/ Dissertation. Germany: Universität Kaiserslautern.

Sun Y, Rao MS, Landis SC, Zigmond RE (1992) Depolarization increases vasoactive intestinal peptide- and substance P-like immunoreactivities in cultured neonatal and adult sympathetic neurons. J Neurosci 12:37173728.

Titmus MJ (1981) Ultrastructure of identified fast excitatory, slow excitatory and inhibitory neuromuscular junctions in the locust. J Neurocytol 10:363-385.

van den Pol AN (2012) Neuropeptide transmission in brain circuits. Neuron 76:98-115.

Vilim FS, Cropper EC, Price DA, Kupfermann I, Weiss KR (1996) Release of peptide cotransmitters in Aplysia: regulation and functional implications. J Neurosci 16:8105-8114.

von Twickel A, Guschlbauer C, Hooper SL, Büschges A (2019) Swing velocity profiles of small limbs can arise from transient passive torques of the antagonist muscle alone. Curr Biol 29:1-12.e7.

Wegener C, Reinl T, Jänsch L, Predel R (2006) Direct mass spectrometric peptide profiling and fragmentation of larval peptide hormone release sites in Drosophila melanogaster reveals tagma-specific peptide expression and differential processing. J Neurochem 96:1362-1374.

Weidler DJ, Diecke PJ (1969) The role of cations in conduction in the central nervous system of the herbivorous insect Carausius morosus. Z Vergl Physiol 64:372-399.
Weiland G, Bässler U, Bucher D (1986) A biological feedback control system with electronic input: the artificially closed femur-tibia control system of stick insects. J Exp Biol 120:369-385.

Weiss KR, Brezina V, Cropper EC, Hooper SL, Miller MW, Probst WC, Vilim FS, Kupfermann I (1992) Peptidergic co-transmission in Aplysia: functional implications for rhythmic behaviors. Experientia 48:456-463.

Whim MD (2006) Near simultaneous release of classical and peptide cotransmitters from chromaffin cells. J Neurosci 26:6637-6642.

Whim MD, Lloyd PE (1989) Frequency-dependent release of peptide cotransmitters from identified cholinergic motor neurons in Aplysia. Proc Natl Acad Sci USA 86:9034-9038.

Whim MD, Lloyd PE (1990) Neuropeptide cotransmitters released from an identified cholinergic motor neuron modulate neuromuscular efficacy in Aplysia. J Neurosci 10:3313-3322.

Wicher D (2001) Peptidergic modulation of an insect $\mathrm{Na}(+)$ current: role of protein kinase A and protein kinase C. J Neurophysiol 85:374-383.

Wistrand M, Käll L, Sonnhammer EL (2006) A general model of G proteincoupled receptor sequences and its application to detect remote homologs. Protein Sci 15:509-521.

Wolf H (2014) Inhibitory motoneurons in arthropod motor control: organisation, function, evolution. J Comp Physiol A Neuroethol Sens Neural Behav Physiol 200:693-710.

Wong MY, Zhou C, Shakiryanova D, Lloyd TE, Deitcher DL, Levitan ES (2012) Neuropeptide delivery to synapses by long-range vesicle circulation and sporadic capture. Cell 148:1029-1038.

Wu M, Pai DK, Tresch MC, Sandercock TG (2012) Passive elastic properties of the rat ankle. J Biomech 45:1728-1732.

Yushkevich PA, Piven J, Hazlett HC, Smith RG, Ho S, Gee JC, Gerig G (2006) User-guided 3D active contour segmentation of anatomical structures: significantly improved efficiency and reliability. Neuroimage 31:1116-1128.

Zakotnik J, Matheson T, Dürr V (2006) Co-contraction and passive forces facilitate load compensation of aimed limb movements. J Neurosci 26:4995-5007. 